\title{
Hygromechanical properties of 3D printed continuous carbon and glass fibre reinforced polyamide composite for outdoor structural applications
}

\author{
G. Chabaud ${ }^{\mathrm{a}}, \mathrm{M}$. Castro ${ }^{\mathrm{a}}, \mathrm{C}$ Denoual $^{\mathrm{b}}$ and A. Le Duigou* ${ }^{\mathrm{a}}$ \\ ${ }^{a}$ Polymer and Composites, Univ.Bretagne Sud, UMR CNRS 6027, IRDL, F-56100 Lorient, France

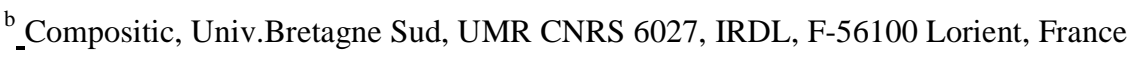 \\ *Corresponding author : antoine.le-duigou@univ-ubs.fr
}

Tel: +33297874586

Fax: +33297874588

\begin{abstract}
$\underline{\text { Abstract }}$
The additive manufacturing of structural composites is a disruptive technology currently limited by its moderate mechanical properties. Continuous fibre reinforcements have recently been developed to create high performance composites and open up encouraging prospects. However, to increase their use, deeper understanding of the relationship between process and induced properties remains necessary. In addition, to apply these materials to engineering applications, it is of high importance to evaluate the effect of environmental conditions on their mechanical performances, particularly when moisture-sensitive polymer is used (PolyAmide PA for instance) which is currently lacking in the literature.

This present article aims to investigate in more detail the relationship between the process, the mechanical behaviour and the induced properties of continuous carbon and glass fibres reinforced with a polyamide matrix manufactured using a commercial 3D printer. In addition, their hygromechanical behaviour linked to moisture effect is investigated through sorption, hygroexpansion and mechanical properties characterization on a wide range of relative humidity (10-98\% Relative Humidity RH).

The printing process induces an original microstructure with multiscale singularities (intra/inter beads porosity and filament loop). Longitudinal tensile performance shows that the reinforcing mechanism is typical of composite laminates for glass and carbon. However, the rather poor transverse properties are not well fitted by the Rule Of Mixture (ROM), thus underlining the specificity of the printing-induced microstructure and an anisotropic behaviour in the material.

Non-negligible (5-6\%) moisture uptake is observed at $98 \% \mathrm{RH}$, as well as orthotropic hygroscopic expansion of PA/carbon and PA/glass composites. The consequences of various moisture contents on mechanical properties are studied, showing a reduction of PA/carbon stiffness and strength of 25 and $18 \%$ in the longitudinal direction and 45 and $70 \%$ in the transverse direction. For PA/glass composites, we obtain a reduction in strength of $25 \%$ in the longitudinal direction, along with a $80 \%$ reduction of stiffness and $45 \%$ in strength in the transverse direction. A wetting/drying cycle underlines reversible phenomena in the longitudinal direction and mainly non-reversible degradation in the transverse direction.
\end{abstract}

Keywords: 3D Printing, Continuous fibre reinforcement, Mechanical properties, Moisture 


\section{Introduction}

Additive manufacturing is a technology which consists of layer-by-layer deposition using numerical 3D model structures [1]. Of the many different 3D printing technologies, the most widespread method is Fused Filament Fabrication (FFF) a material extrusion process. Owing to this technology, a wide range of materials can be processed, especially polymers and composites [2-7]. Thus, FFF allows the rapid printing of very intricate parts, without using complex tools and with reduced solid waste emissions, leading to a reduction of production costs [4,5]. FFF is also gaining interest because it offers a solution to reduce maintenances especially in applications in extreme conditions like polar or ocean expeditions, ocean races (America's cup for example), civil or military (US Navy for example) ocean transports and drones. Indeed, in these conditions it is difficult to quickly repair materials or to bring spare parts. 3D printing offers an encouraging solution in the case where printed materials offer also high mechanical performance and durability.

However, FFF printed thermoplastic materials often show mediocre mechanical properties partly due to the lack of pressure applied during the process $[8,9]$. Consequently, many studies have investigated the addition of reinforcing fibres within the polymer filament. Several studies have shown that the addition of short fibres allows the printing of parts with better mechanical properties [10-14].

Nevertheless, addition of short fibres within the polymer matrix for FFF filaments is often limited to a maximum fibre volume fraction of about $50 \%$ because of the prohibitively high viscosity value of the molten composite filament. The direct consequence is that these short-fibre reinforced filaments have only a limited use for structural applications.

Recently, to overcome these limitations and to fill the gap between printed parts and conventionally manufactured composites, great efforts have been made to develop continuous fibre reinforcement in the printed parts. Different strategies have been used, such as the modification of the printing nozzle to ensure impregnation of the initially dry fibres by the matrix within the printing head (while printing) [15-18]. Nevertheless, materials developed with this process exhibit a poor fibre-matrix interface because of the lack of compaction during the printing, which explains why research teams have developed 'ready-to-print' continuous-reinforced filament [19,20]. Several studies have investigated this new printing technique [21-24] and have reported improved mechanical properties compared to short-fibre reinforced printed composites. For example, Yamawaki et al. [19] have worked on PolyAmide (PA) reinforced with continuous carbon fibre and have obtained parts reaching an ultimate tensile strength of $624 \mathrm{MPa}$ for a fibre volume fraction of $20 \%$. In this way, these authors obtained parts with 8.6 times higher ultimate tensile strength when using a lower fibre fraction than with shortfibre reinforced printed composites. Despite the better mechanical properties that can be attained through this improved technology, and the potential for structural applications, there are still some drawbacks. Indeed, studies have shown that the printed parts exhibit a porosity level of around 10\%, which is very high compared to traditional composite manufacturing processes $[25,26]$. For outdoor 
applications submitted to temperature and moisture variations like in marine engineering (pulley, chandlery, propeller, submarine drones, marine turbine...) the moisture sensitivity of the polymer matrix could limit their application especially if PolyAmide (PA) is used. In addition, a microstructure effect (i.e. increased porosity) could also affect the moisture sorption, the transport of the material as well as a whole set of hygromechanical properties.

In this study, we use continuous glass fibre as well as continuous carbon fibre reinforced PA filaments to print composite parts via a commercial 3D printer. First of all, the longitudinal and transverse mechanical behaviour and properties of printed parts with varying fibre volume fraction are measured through tensile tests. The reinforcing mechanism is evaluated by comparing the properties of carbon and glass reinforced composites measured by tensile tests with values obtained by back-calculation using the Rule of Mixture (ROM). Then, microscopical analysis is carried out to describe extensively the microstructure and defects induced by the printing process.

Finally, with the aim of using continuous fibre reinforced 3D printed parts, to make use of their better structural performance in outdoor applications, we evaluate and discuss sorption and swelling behaviours along with the mechanical responses under different moisture conditions.

\section{Materials and test methods}

\subsection{Part manufacturing with Fused Filament Fabrication (FFF)}

The 3D printer used in this study is a MarkTwo 3D printer provided by Markforged ${ }^{\circledR}$, which is driven by a web interface (Eiger.io) developed by Markforged ${ }^{\circledR}$. The filaments, made of multiple strands of carbon or glass fibres coated with polyamide matrix are also provided by Markforged ${ }^{\circledR}$ [9]. Two spools of filaments are available during the printing, i.e. one of neat PA6 filament and one of continuous Carbon Fibre or continuous Glass Fibre reinforced PA filament. In the following, we refer to continuous carbon and glass fibre reinforced PA filaments (or printed composites) as cCF/PA and cGF/PA, respectively. Note that a pure polyamide 6 (PA 6) layer is always deposited on the bottom and on the top of each sample, to avoid dismantling the part during printing [22], as well as at the perimeter of each printed layer. This gangue-like coating is referred to as "Roof \& floor layers" and "wall layers" and represents the number of layers deposited on the top, on the bottom and on the edge, respectively (see Figure 1).

\section{Figure 1}

The following printing parameters were used to prepare a rectangular specimen. The fill pattern is selected as rectangular, with a fill density of $100 \%$. To maximize the fibre volume fraction, 'Roof \& Floor' as well as 'Wall' layers were set at 1 . The printing speed of fibre filaments is estimated around 
$14 \mathrm{~mm} / \mathrm{s}$. This speed is slow regarding other FDM 3D printer but for 3D printing of continuous fibre composite, printing speed has to be slow enough so as to avoid bead pull-out from the plate.

Furthermore, a slow printing speed induce a slower cooling which promote interdiffusion between printed beads and enhance transverse and interlaminar properties of printed parts.

Table 1

The thicknesses of the continuous carbon, glass fibre printed layers and pure PA- 6 were set at 0.125 , 0.1 and $0.2 \mathrm{~mm}$, respectively. Supports, brim and expanded features were not used. The filaments provided by Markforged ${ }^{\circledR}$ have a fixed preset fibre volume fraction measured by thermogravimetric analysis (35\% vol for carbon filaments and $39 \%$ vol for glass filaments), while the amount of fibre in the material is controlled by the thickness $e_{\mathrm{f}}$ and the global thickness $\mathrm{e}_{\mathrm{T}}$. This specific feature is a notable drawback because fibre volume fraction, and hence also the material properties, will depend on the material geometry. For this purpose, three different configurations for each material were used as summarized in Table 1.

\subsection{Tensile tests on single fibres and composites}

Tensile properties of single carbon and glass fibre were characterized according to ISO 11566.

Beforehand, reinforced filaments had been immersed in a 98\% solution of formic acid to dissolve PA matrix and extract single fibres [27]. Afterward, single fibres were stuck on paper supports with a gauge length of $10 \mathrm{~mm}$ [28] and cross-sectional diameters were measured with optical microscopy at three points along the fibre. Finally, tensile tests were carried out with a MTS Synergie RT/1000 tensile machine using a $2 \mathrm{~N}$ capacity load cell at $23^{\circ} \mathrm{C}$ and $50 \% \mathrm{RH}$ with a crosshead speed of $1 \mathrm{~mm} / \mathrm{min}$. For each batch, 50 samples were tested.

For composites, sample tests were carried in accordance with ASTM D3039. The sample dimensions were $100 \mathrm{~mm}$ x $15 \mathrm{~mm}$ x variable Thickness, to obtain varying fibre volume fractions (Table 1). Whole sample thickness (including coating PA-6) was taken into account to calculate the tensile stress. Because of the high anisotropy induced by the continuous fibre reinforcement, two different patterns were printed following the $x$ and $y$ axis, i.e. in order to evaluate the longitudinal and transverse mechanical properties. End tabs made of a Polyamide/glass composite laminate were glued to the sample with Loctite $406 ®$.

Mechanical behaviour of longitudinal carbon fibre was measured on an Instron 8803 test machine with a 50kN capacity load cell and Kyowa KFGS-10-120-C1-11 strain gauges. The crosshead speed was set at $1 \mathrm{~mm} / \mathrm{min}$ according to ASTM D3039. Tensile modulus was measured in a deformation range between $0.025 \%$ and $0.1 \%$. Tensile tests were performed at room temperature $\left(23^{\circ} \mathrm{C}\right)$ and at $50 \%$ Relative Humidity (RH). Moreover, no standards are available that deal with the mechanical characterization of printed composites. 


\subsection{Sample storage and gravimetric measurements}

The tensile tests specimens were stored in chambers with Relative Humidity (RH) controlled by a saturated solution of potassium hydroxide $(\mathrm{KOH})$, magnesium chloride $\left(\mathrm{MgCl}_{2}\right)$, sodium chloride $(\mathrm{NaCl})$ and potassium sulphate $\left(\mathrm{K}_{2} \mathrm{SO}_{4}\right)$ so as to reach a $\mathrm{RH}$ of $10 \%, 30 \%, 75 \%$ and $97 \%$ respectively. Tensile tests specimens were also stored and in a lab room at 50\% RH. All samples were stored at room temperature $\left(23^{\circ} \mathrm{C}\right)$. Samples were used after reaching saturation, i.e. when the weight was stabilized. Samples $20 \mathrm{~mm}$ (L) x $20 \mathrm{~mm}$ (w) x $4 \mathrm{~mm}$ (t) were printed to evaluate the moisture uptake and the hygroscopic expansion. Volumetric measurements were performed with a Mitutoyo micrometer IP 65 and gravimetric analyses using a Fischer Scientific PAS214C balance $\left(10^{-4} \mathrm{~g}\right)$.

\subsection{Thermogravimetric analysis (TGA) and Differential Scanning Calorimetry (DSC)}

The fibre volume fractions were determined by thermogravimetric analysis according to the ASTM D3171-15 and performed with a Mettler-Toledo Thermal Analysis instrument (STARe System). A temperature ramp of $10 \mathrm{~K} / \mathrm{min}$ from $25^{\circ} \mathrm{C}$ to $400^{\circ} \mathrm{C}$ was used and analyses were conducted under a nitrogen atmosphere. As, supplier does not explicit the polymer nature, Dynamic Scanning Calorimetry (DSC) is carried out to ascertain the nature of the polyamide in the printable filaments. A first temperature ramp of $10 \mathrm{~K} / \mathrm{min}$ was carried out from $25^{\circ} \mathrm{C}$ to $350^{\circ} \mathrm{c}$ to erase the thermal history. Samples were then cooled down to $-10^{\circ} \mathrm{C}$ at $20 \mathrm{~K} / \mathrm{min}$ and then a second temperature ramp of $10 \mathrm{~K} / \mathrm{min}$ from $-10^{\circ} \mathrm{C}$ to $350^{\circ} \mathrm{C}$ was performed to measure the thermal properties of polymers (Glass transition temperature $\mathrm{Tg}$, melting temperature $\mathrm{T}_{\mathrm{m}}$, crystallization temperature $\mathrm{T}_{\mathrm{c}}$ and enthalpy). Thermogram have evidenced that polyamide 6-I (PA6-I) and polyamide 6 (PA6) should be the polymer matrix for carbon and glass reinforced filaments respectively. The polymer coating is a polyamide 6 (PA6).

\subsection{Porosity and microstructure analysis}

Porosity measurement were performed using the standard ASTM D2734-16 2009. The equation related to this standard is:

$$
\phi=1-\rho_{C}\left(\frac{1-w_{F}}{\rho_{m}}+\frac{w_{F}}{\rho_{F}}\right)
$$

In this equation, $\Phi$ is the porosity, $\rho_{\mathrm{C}}$ the composite density, $\mathrm{w}_{\mathrm{f}}$ the fibre weight fraction, $\rho_{\mathrm{m}}$ the matrix density and $\rho_{\mathrm{f}}$ the fibre density. Density measurements were performed through volumetric and gravimetric tests.

Microstructures of the reinforced filament and printed parts were observed with optical microscopy (Olympus BX51) with different magnifications (x5, x10, x20). Image analysis was used with ImageJ software to evaluate the porosity. Porosities were manually colour coded, then images were binearized and the amount of black areas was finally calculated using the software. Ten images were used for each system. 


\section{Results and discussion}

\subsection{Microstructure description}

Firstly, the microstructure of the as-received filaments was investigated through optical observations.

Optical images of the filament cross-sections were acquired to investigate the pre-printing geometrical characteristics as well as the state of fibre dispersion within the polymer matrix. Typical images are presented in Figure 2.

Figure 2

As can be seen in Figure 2 ( $a, b$ and d, e), the as-received filaments exhibit irregular sections with an average diameter of $380 \mu \mathrm{m}$ and $332 \mu \mathrm{m}$ for continuous Carbon Fibre/PA (cCF/PA) and continuous Glass Fibre/PA (cGF/PA), respectively. These variations may be due to the fibre coating process used to prepare the filament. Moreover, impregnated fibres are not homogeneously dispersed in the polymer matrix. Indeed, the fibres are agglomerated and not spread evenly in the filament, (almost reflecting the size and shape of the initial fibre yarn) leading to areas that are very rich in fibres, and consequently, other areas that are very rich in matrix, thus limiting or reducing the homogeneity of the subsequently printed part. Furthermore, as illustrated in Figure 2 (yellow points in $\mathrm{c}$ and $\mathrm{f}$ ), the asreceived filaments also exhibit matrix-free zones where the reinforcing fibres remain nonimpregnated, implying internal porosity of the as-received filaments. These non-impregnated areas are more common in the carbon filaments and exhibit $40 \%$ higher internal porosity than the glass reinforced filaments (Table 2). The fibre profile is also different between carbon and glass, with glass fibres exhibiting a larger average diameter $(8.8 \pm 0.5 \mu \mathrm{m})$ than carbon fibres $(6.9 \pm 0.7 \mu \mathrm{m})$. Nevertheless, the diameters of glass fibre are less than conventional E-glass fibres $(\mathrm{d} \approx 20 \mu \mathrm{m})$.

After filament characterization, we studied modifications of the microstructure induced by the process step. Two planar areas are observed, a cross-sectional view and an in-plane view following planes $(\mathrm{y}, \mathrm{z})$ and $(\mathrm{x}, \mathrm{y})$, respectively (see Figure 1). Images of cross-sectional view are presented in Figure 3.

Figure 3

Figure 3(a and d) shows some panoramic images of cross-sectioned samples, for cCF/PA and cGF/PA, respectively. For both systems, recurrent large void areas are present in both specimens. These images are magnified in Figure 3(b and e) for carbon reinforced samples and glass reinforced samples, respectively. The void areas result from a non-overlap between two adjacent printed beads, and correspond to inter-bead porosities representing the major part of the voids (around 85\% of global void content for $\mathrm{cGF} / \mathrm{PA}$ and $60 \%$ for $\mathrm{cCF} / \mathrm{PA}$ ). Other porosities are located between layers as well as within each filament (intra-bead porosity). Porosities in interlaminar areas are due to the lack of pressure and inhomogeneous temperature field which reduce interdiffusion efficiency. Intra-bead porosities, especially for $\mathrm{cCF} / \mathrm{PA}$, surprisingly appear in the printed beads. Several hypotheses can be raised such as the initial heterogeneity of filament diameter, lack of matrix wetting in fibre-rich areas or loss of a third component. Its origin still has to be deeper investigated. 
During the printing process, the filaments undergone a flattening. The $379 \mu \mathrm{m}$ and $332 \mu \mathrm{m}$ wide filaments become layers with thicknesses of $127 \mu \mathrm{m}$ and $101 \mu \mathrm{m}$ for continuous carbon and glass fibre polyamide composites, respectively, thus dividing by 3 the initial filament size. This flattening may reduce substantially the intra-bead porosity.

Hence, these different kinds of porosity lead to a considerable raising of porosity during the printing process, reaching $15.1 \%$ for $\mathrm{cCF} / \mathrm{PA}$ parts and $12.3 \%$ for $\mathrm{cGF} / \mathrm{PA}$ parts. The higher porosity for carbon reinforced parts can be explained by the higher filament porosity. This higher intra-bead porosity can be observed on Figure 3(c and f).

Table 2

In-plane images of cCF/PA and cGF/PA samples are presented in Figure 4a and c, respectively.

\section{Figure 3}

On these images, loops are created on the edge of the samples. These loops are due to the printing process; when the nozzle reaches the edge of the part, the printed head turns back, which folds back the printed beads, thus creating the loops. The turning radii for both carbon and glass samples are measured at about $0.6 \mathrm{~mm}$ (Table 3). Folding induces stress concentration in the printed bead and causes a local fibre breakage in the carbon beads (Figure 4(b)) due to their low toughness. This phenomenon is not observed for glass fibre composites (Figure 4(d)). Moreover, bead folding leads to very rich fibre areas and also resin-rich regions within the loop. Loop areas are different between carbon and glass reinforced samples $\left(0.42 \mathrm{~mm}^{2}\right.$ for carbon and $1.04 \mathrm{~mm}^{2}$ for glass $)$ due to the different filament size. Thus, glass printed parts have an inter-bead distance 3 times larger than the carbon printed parts $(0.31 \mathrm{~mm}$ for $\mathrm{cGF} / \mathrm{PA}$ and $0,13 \mathrm{~mm}$ for $\mathrm{cCF} / \mathrm{PA})$.

\section{Table 3}

Hence, the printing process induces many defects that can be fairly compared with those observed in Automatic Fibre Placement (AFP). In the latter case, local misalignment, stirring (in-plane buckling) or overlapping of tapes are considered as singularities rather than flaws, i.e. inherent to the process, which need to be taken into account into the design/dimensioning process.

\subsection{Longitudinal and Transverse tensile behaviour and properties}

In this section, we evaluate the tensile modulus and strength of the neat PA matrix (as a reference), continuous carbon and glass polyamide printed parts in longitudinal and transverse directions. For $\mathrm{cGF} / \mathrm{PA}$ and $\mathrm{cCF} / \mathrm{PA}$, the mechanical tests are performed with varying fibre volume fractions (from 13 to $35 \%)$. To vary the fibre volume fraction, different thicknesses $(0.5 ; 1 ; 2 \mathrm{~mm})$ were printed and 
samples were prepared where the polyamide coating was manually removed. Thus, for $\mathrm{cCF} / \mathrm{PA}, 0.5$ mm-thick samples correspond to $12.9 \%$ volume fraction, $1 \mathrm{~mm}$ represents $22.6 \% \mathrm{Vf}, 2 \mathrm{~mm}$ represents $30 \% \mathrm{Vf}$ and samples without polyamide coating exhibit a Vf of 35\%. For cGF/PA, 0.5-mm-thick samples correspond to $21.5 \% \mathrm{Vf}, 1$-mm-thick samples correspond $28 \%$ Vf, $2 \mathrm{~mm}$ represents $33.1 \%$ and, finally, samples without polyamide coating exhibit a Vf of 39\%. The main results are summarized in Figure 5. Figure 5(a) shows a typical stress versus strain curve for 1-mm-thick samples (22.6\%). For both reinforced composites, the stress increases almost linearly with the applied strain up to $1.1 \%$ and $2.2 \%$, at which point rupture occurs for carbon and glass, respectively, expressing a brittle behaviour. This behaviour is similar to that observed in single fibres (not shown here) and indicates that the loading is well transferred to the reinforcing fibres.

Figure 5

For both kinds of fibres, the longitudinal specimen breaks perpendicular to the load without necking, highlighting the brittle nature of the behaviour (Figure 6). Moreover, debonding, delamination and matrix shear are present in both samples, but are more marked for cGF/PA. This difference can be due to the microstructure effect with the greater inter-bead distance for cGF/PA samples which causes lower cohesion.

Figure 6

Figure 5(b-c) shows the evolution of tensile modulus and ultimate tensile stress as a function of fibre volume fraction for carbon and glass reinforced samples. As expected, the modulus increases linearly with carbon or glass fibre fraction. Actually, for cGF/PA, higher fibre volume fraction than $30 \%$ are achieved by means of coating polyamide (walls + top + bottom) removal. It drastically changes rupture mode (debonding between beads instead of fibre breakage) and induce lower ultimate tensile stress.

Single fibre tensile tests yield values of $68 \pm 7 \mathrm{GPa}$ for glass fibres and $161 \pm 10 \mathrm{GPa}$ for carbon fibres tensile modulus, which are slightly lower compared with typical E-glass and carbon fibres. By applying a simple Rule Of Mixture (ROM) to these data and using the tensile modulus of polyamide measured by tensile tests $\left(\mathrm{E}_{\mathrm{exp} P \mathrm{~A}}=0.29 \pm 0.1 \mathrm{GPa}\right)$, we can estimate the composite properties $\left(\mathrm{E}_{\mathrm{ROM}}\right.$ ${ }_{\mathrm{cCF} / \mathrm{PA}}=37 \mathrm{GPa}$ and $\mathrm{E}_{\mathrm{ROM} \mathrm{CGF/PA}}=18 \mathrm{GPa}$ for $\mathrm{Vf}=22.6 \%$ for $\mathrm{cCF} / \mathrm{PA}$ and $\mathrm{Vf}=21.5 \%$ for $\mathrm{cGF} / \mathrm{PA}$, respectively). It should be noted that low modulus was measured for printed pure PA samples regarding literature data for classic manufacturing process. This observation is well known and has been evidenced in the literature for other polymers such PLA and ABS [29,30]. 
Moreover, the ROM can be modified by taking account of the real porosity content $\Phi$ (Equation 2) [31]:

$$
E_{C}=E_{T H}(1-\Phi)^{2}
$$

where $\mathrm{E}_{\mathrm{th}}$ is the theoretical modulus without porosity and $\Phi$ the porosity content. In this case, the

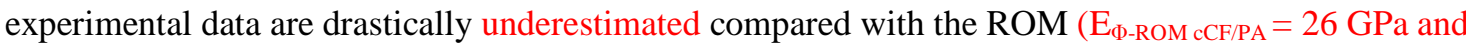
$\mathrm{E}_{\Phi-\mathrm{ROM} C \mathrm{GF} / \mathrm{PA}}=11 \mathrm{GPa}$ ), which means that porosity has only a weak influence on tensile modulus. This low influence of porosity on tensile modulus is confirmed in the literature [32-34] on carbon-epoxy laminates manufactured with conventional processing routes.

Mechanical properties of composites are greatly enhanced compared to pure PA6. Indeed, for $\mathrm{Vf}=22.6 \%$, ultimate tensile stress is 23 times higher and 19 times higher for carbon and glass, respectively, while the tensile modulus is 137 times higher and 63 times higher for carbon and glass respectively. Then, we compare specific mechanical properties with the mechanical properties of short fibre composites developed by Fused Filament Fabrication (FFF) as described in the literature as well as with aluminium and conventionally manufactured composites (Figure 7). This comparison should be taken with caution as different fibre type, fibre orientation and fibre volume fraction may be different despite having a strong effect on the composite property.

Continuous fibre printing allows a great improvement in mechanical properties compared to shortfibre printed composites. For the same fibre volume fraction (22.6\%), the specific modulus is 11 times higher and the specific tensile strength is 7 times higher with $\mathrm{cCF} / \mathrm{PA}$ than with the short-fibre printed composite (Figure 7). Moreover, these samples have better properties than aluminium. However, the mechanical properties of $\mathrm{cCF} / \mathrm{PA}$ samples are poorer than conventionally manufactured unidirectional composites, the specific tensile strength being around 2.5 times lower. Their specific tensile strength is around 1.5 times lower than composites manufactured by hot compression moulding [25] due not only to the inherent microstructure (porosity, heterogeneity) induced by printing, but also the lower fibre volume fraction. Indeed, fibre volume fraction is limited by the as-received filament which has a low fibre volume fraction (35\% vol for carbon filaments and $38.8 \%$ vol for glass filaments) compared to conventional composites (50-60\%).

Furthermore, the mechanical properties measured here can be compared to data compiled from the literature as well as data provided by MarkForged. Hence, our measured results are in the same range obtained by other research teams. For instance, MarkForged, Justo et al. and Goh et al. estimate the ultimate tensile stress at $700 \mathrm{MPa}, 701 \mathrm{MPa}$ and $600 \mathrm{MPa}$, respectively, for samples reinforced with $40 \%$ of carbon fibres $[6,24,26]$. Also, MarkForged and Justo et al. found a tensile modulus of $54 \mathrm{GPa}$ and $68 \mathrm{GPa}$ for $\mathrm{CCF} / \mathrm{PA}$ with the same fibre volume fraction of $40 \%[6,26]$. Comparatively, the values obtained in our study for cCF/PA with $35 \%$ carbon fibre is about $534 \mathrm{MPa}$ for ultimate tensile stress and $60 \mathrm{GPa}$ for tensile modulus. 


\section{Figure 7}

To evaluate the anisotropy of the material, we tested the mechanical properties of printed parts in the transverse direction. The results are reported in Figure 5(d-f). Typical behaviour of cCF/PA and cGF/PA (1mm thick) for transverse specimens are shown in Figure 5(d) and are compared to pure nylon samples as a reference. Hence, stress increases linearly until $0.6 \%$ and $0.8 \%$ for carbon and glass reinforced samples, respectively, and then plastic deformation occurs until rupture at $1 \%$ and between 2 and 3\% for carbon and glass specimens, respectively. This behaviour is characteristic of a ductile behaviour. This behaviour is also illustrated by Figure 8, which gives a detailed view of the rupture mechanism in transverse profiles of carbon and glass samples.

\section{Figure 8}

For both materials, specimen breakage is due to the shearing failure of the polymer coating, printed at $45^{\circ}$ and at $-45^{\circ}$ to the longitudinal direction, for the top and for the bottom layer, respectively, as well as adhesive rupture between two adjacent beads (shown by Figure 8(b and e)). Indeed, the overlap is poor between the beads, so, during tensile tests, two non-overlapping filaments move apart from each other and, consequently, the tensile load is not transferred to the reinforcing fibres. Thus, the load is transferred to the polyamide coating (figure 8f), explaining the ductile behaviour.

This non-overlapping can also be seen on Figure 8(c, f), which shows the result of an excessive deformation applied to the material. For these samples, the polyamide coating breaks in shear and filament unwinding is induced. For carbon samples, bead rupture occurs in the folded area because of the initial fibre failure (Figure $4 b$ ).

Figure 5(e-f) represents the variation of transverse properties as a function of fibre volume fraction. Unlike longitudinal samples, the transverse specimen exhibits different trends for modulus and strength, both for carbon and glass fibre composites. For the modulus, continuous Carbon Fibre/PA samples exhibit an improvement with increasing fibre fraction unlike continuous Glass Fibre/PA. As regards strength, $\mathrm{cCF} / \mathrm{PA}$ and $\mathrm{cGF} / \mathrm{PA}$ both show poorer properties than PA6 with a drastic reduction of stress at break $(\approx-70 \%)$ with fibre fraction. This trend can be explained by a weak bead interface as well as the presence of fibres that affect the strain field in the surrounding matrix, particularly when the fibre distribution is heterogeneous. In addition, both the transverse as well as the out-of-plane properties of laminates are very sensitive to defects i.e. porosity content and localization $[35,36]$. The ratio of longitudinal to transverse properties (Anisotropic Ratio $=\mathrm{AR}$ ) evolves with fibre type. For $23 \%$ fibre volume fraction, the AR in carbon samples is 32 for modulus and 70 for strength. For $21 \%$ fibre volume fraction and cGF/PA, the AR is 160 for modulus and 56 for strength. Thus, transverse properties are clearly a limiting factor, which can be further amplified by the printing process. These observations highlight the need to carry out a careful optimized stacking sequence before printing the laminate. 
Applying an inverse Rule Of Mixture for $\mathrm{cCF} / \mathrm{PA}$ and $\mathrm{cGF} / \mathrm{PA}(\mathrm{Vf}=22.6 \%$ and $\mathrm{Vf}=21.5 \%$, respectively) and using a transverse modulus of $7 \mathrm{GPa}$ for carbon fibres and $72 \mathrm{GPa}$ for glass fibres [37] leads to a large discrepancy for calculated transverse modulus with the experimental values, especially for cGF/PA ( $0.38 \mathrm{GPa}$ for both $\mathrm{E}_{\mathrm{ROM} \text { cCF/PA }}$ and $\left.\mathrm{E}_{\mathrm{ROM} \text { cGF/PA }}\right)$. cCF/PA shows a measured transverse modulus of $1.03 \mathrm{GPa}$, while cGF/PA shows a modulus of $0.19 \mathrm{GPa}$. This difference can be explained by the structural effect of the printed microstructure whereby the PA6 coating contributes to the transverse behaviour, but also the presence of porosity which disturbs the load transfer. Thus, the mechanical properties in transverse direction cannot be predicted from the fibre volume fraction. Moreover, very weak properties in the transverse printing orientation is one of the most critical drawbacks in the 3D printing of continuous fibres.

Because of the well-known water sensitivity of PA6 polymer, the mechanical properties are likely to vary in a humid environment. For this study, we use a thickness of $1 \mathrm{~mm}$ to maintain a set fibre volume fraction.

\subsection{Evolution of mechanical properties in humid environments}

\subsubsection{Moisture uptake and hygroscopic expansion}

Figure 9 shows the variation of moisture content (MC) as a function of relative humidity for cGF/PA and $\mathrm{cCF} / \mathrm{PA}$. The global sorption behaviour is similar between samples and can be well fitted by the Park model [38] expressed by equation (5).

$C=\frac{A b_{L} a}{1+b_{L} a}+s a+\frac{K_{c} s^{n} a^{n}}{n}$

where $C$ represents the water content in the material, $a$ the water activity, $A$ the Langmuir capacity constant, $b_{L}$ Langmuir affinity constant, $s$ the Henry solubility coefficient, $K_{C}$ the equilibrium constant for the cluster formation and $n$ the number of water molecules per cluster [39].

Therefore, the moisture sorption by PA matrix follows a three-step sorption typical of porous materials. At low water activity $(\mathrm{a}<0.1)$, the water sorption is driven by Langmuir sorption where water is absorbed by the free amide bonds. In the present study, the effect of Langmuir sorption is ignored because of the lack of data on water activity below 0.1 , so the Langmuir parameters are set to 0 . At higher water activity $(0.1<\mathrm{a}<0.6)$, the sorption follows a linear fit according to Henry's law. Finally, at high water activity ( $>0.6$ ), water clusters appear in the material according to a FloryHuggins type sorption.

Figure 9

However, a slight difference of amount of moisture content is observed between both systems. Indeed, at $98 \% \mathrm{RH}$ cGF/PA samples absorbed an amount of water $30 \%$ higher than carbon counterparts despite 
their larger porosity content (Table 1). Higher moisture content for glass samples can be thus explained by difference of matrix nature. Indeed, DSC analysis (not shown here) has established that cGF/PA6 filaments showed a glass transition temperature $(\mathrm{Tg})$ at $50^{\circ} \mathrm{C}$ and a melting temperature of $200^{\circ} \mathrm{C}$. $\mathrm{CCF} / \mathrm{PA}$ filament is an amorphous polymer, with $\mathrm{Tg}$ at $135^{\circ} \mathrm{C}$, corresponding to polyamide $6-\mathrm{I}$ which is a semi-aromatic polyamide. In the literature, PA6 absorbs higher amount of water (3\% at $50 \% \mathrm{RH})$ than PA 6-I (2\% at 50\% RH), leading to a higher water uptake by cGF/PA [40]. One consequence of water sorption is the hygroscopic swelling. Swelling strains $\varepsilon^{h}$ are calculated by equation 4 where $\beta^{h}$ the hygroscopic swelling coefficient and MC the moisture content in the material.

$$
\varepsilon^{h}=\beta^{h} M c
$$

The swelling of cCF/PA and cGF/PA printed parts as a function of moisture uptake by the material are represented in Figures 10 (a) and (b) respectively. The swelling is evaluated in (x, y, z) directions depicting longitudinal, transverse and out-of-plane directions. Hygroscopic swelling monotically increases with moisture content.

Figure 10

In the longitudinal axis (x), swelling is prevented by the stiffness induced by the fibre orientation. Transverse and out-of-plane directions exhibit a drastic difference in swelling properties, while the laminate properties are assumed to be transversally isotropic.

This phenomenon may be explained by the sample microstructure. Because of the non-overlap between some printed beads in the transverse direction, and thus the higher porosity distributed there, swelling strains might not be transmitted efficiently compared to the out-of-plane direction.

Porosities in the transverse direction may act as connections in series, in which case all porosities will reduce the induced swelling. Otherwise, porosities in the out-of-plane direction will act as parallel connections, implying that porosities undergone hygroscopic swelling separately, leading to a lower mitigation of swelling.

Moreover, parts reinforced with glass fibres show a higher hygroscopic swelling than carbon samples because of the higher water content and lower porosity in these samples.

Based on equation 4, we can assume a linear relationship between hygroscopic strain and moisture content. However, by plotting the slope i.e hygroscopic coefficient $\beta^{\text {h }}$ against moisture content of cCF/PA and cGF/PA as reported in Fig 10 (c) and (d), respectively, we observe a reduction of $\beta^{\mathrm{h}}$ with moisture for $\mathrm{CCF} / \mathrm{PA}$ i.e when free water transport occurs through cluster formation but also through voids. For $\mathrm{cGF} / \mathrm{PA}, \beta^{\mathrm{h}}$ rises along with moisture content up to $3 \%$, after which it decreases. Measured values of $\beta^{\mathrm{h}}$ are also compared with the literature. Several research teams have worked on various polymer matrices (epoxy, polyamide, etc.) with different treatments (storage in moisture-controlled chambers, immersion) [41-43]. These studies note a linear increase of hygroscopic swelling with 
moisture content. This behaviour indicates a constant hygroscopic coefficient despite changing the water content in the composite.

\subsubsection{Evolution of mechanical behaviour}

Once a steady-state regime is reached under different moisture conditions (9-98\% RH), we can measure the longitudinal and transverse properties of continuous carbon and glass printed samples (Figure 11). The fibre volume fraction is set at $22.6 \%$ and $29 \%$ for cCF/PA and cGF/PA, respectively, for a thickness of $1 \mathrm{~mm}$.

Figure 11

The moisture content as conditioned by various environments leads to modifications of the tensile properties of glass and carbon printed composites. For carbon samples, the longitudinal tensile modulus and tensile strength are fibre dependant but are linearly reduced by about $25 \%$ and $18 \%$, respectively, between 9\% RH and 98\% RH. Failure mode of cCF/PA (not shown here) stored at 95\% RH exhibits more debonding than samples stored at $15 \% \mathrm{RH}$. This difference in failure mode highlights the consequences moisture-induced degradation such as differential swelling between layers which induce a weakening of part cohesion.

Surprisingly, the cGF/PA tensile modulus is stable over a range of moisture variation despite the sensitivity of the PA matrix to moisture. Tensile strength decreases by $25 \%$. The small decrease of cGF/PA stiffness might be explained by the in-plane microstructure; indeed, the non-overlapping in glass reinforced composites might diminish the consequences of hygroscopic swelling.

Moreover, water sorption by the polyamide matrix induces a weakening of the matrix/fibre interface. Downes et al. have studied the PA6/carbon interface and have observed a drop of IFSS (Interfacial Shear Strength) between tests processed at $0 \% \mathrm{RH}$ and at 90\%RH [44]. Reduction of fibre/matrix adhesion is due to the reduction of hydrogen interactions as well as modification of internal stress state in the interface region because of differential swelling between the fibre and matrix [43]. The fibre/matrix interface is crucial in controlling the mechanical properties of composite materials, so interface degradation leads to a diminishing of composite mechanical performances. Reversibility of tensile properties is tested here after one wetting at 98\% RH (until stabilization) and subsequent drying at $9 \% \mathrm{RH}$. Both $\mathrm{cCF} / \mathrm{PA}$ and $\mathrm{cGF} / \mathrm{PA}$ samples shows a complete reversibility of stiffness and a slight reduction (-5\%) of strength, highlighting a predominant moisture-induced plasticizing effect of the PA matrix. Slight irreversible degradation could be attributed to the hygroscopic stress state within materials, which is influenced by the heterogeneous fibre distribution among printed layers and differential hygroscopic properties between components.

As shown on Figure 11(b,d), the influence of moisture content on transverse properties is very dramatic. Water sorption greatly reduces the mechanical properties, but with different trends between 
carbon and glass fibres. Indeed, for carbon samples, the transverse modulus and strength are reduced by around $45 \%$ and 70\%, respectively, between 9 and 98\% RH. However, these trends are not monotonous and show a slight increase at low moisture content $(<1 \%)$ and then a decrease. This may be due by the evolution of stress state at the fibre/matrix interface which may be compressive due to higher hygroexpansion of the polymer compared to the fibre. Above $1 \%$ of moisture content, reduction of fibre/matrix interactions as well as matrix stiffness may lead to reduction of transverse properties of the laminates. Further works are needed to confirm this hypothesis.

Glass samples also exhibit reduction in transverse properties but in a monotonic way. Transverse stiffness and strength are reduced by $80 \%$ and $45 \%$, respectively.

Reversibility of transverse properties, measured after sorption-desorption cycles, shows that cCF/PA have an irreversible reduction in strength of $40 \%$, while stiffness is entirely recovered. cGF/PA exhibits an irreversible reduction of modulus (-65\%) and strength $(-25 \%)$.

Transverse properties are basically controlled by the matrix and the fibre/matrix interface performances but also by the composite microstructure. Although plasticizing of the polyamide matrix once again occurs in this loading direction, the mechanical properties show an irreversible lowering which is mainly due to the microstructure of printed samples as mentioned above (Figure 8). Indeed, inter-bead cohesion and weakening with increased moisture content is of primary importance compared to fibre/matrix interface and transverse properties of reinforcing fibres (Figure 8). In addition, the polyamide coating influences the transverse behaviour of the fibre and its moistureinduced degradation.

\section{Conclusion}

3D printed composites are increasingly being studied, but their mechanical performances are still rather poor. This explains why continuous glass and carbon fibre-reinforced composites have been recently considered in the literature as well as in the present study.

The influence of the printing process has been highlighted by the high porosity of the material used, which show 8 times higher porosity than in the filaments, being heterogeneously distributed in the laminate. Interbead areas represent the main location of porosity. The turning back of filaments, which evidently occurs during the printing process, also creates a singular microstructure which needs to be taken into account in part manufacturing. These turn-backs also imply the heterogeneity of fibre content and potential stress concentration. Fibre volume fraction is currently limited and evolves with sample thickness due to the specific printing configuration. Thus, the fibre content of printed parts is geometry-dependant and, consequently, this applies to their mechanical properties. This study investigates the mechanical properties of carbon and glass specimens. Longitudinal properties are influenced by fibre volume fraction following a typical Rule Of Mixture (ROM) where fibre properties 
are evaluated by single tensile tests. As fibre volume fraction varies with composite thickness, predicting the properties of complex parts requires more detailed research. Even if longitudinal properties are only slightly influenced by process induced-defects, transverse properties are dramatically altered. Indeed, inverse ROM does not allow a fit with the experimental data. Transverse properties are currently a limiting factor for the development of 3D printed parts but also for property prediction. Because of the marked influence of the printing process, studies have concentrated on printed part behaviour rather than material properties. Furthermore, it should be noted that there are so far no standards dealing with the characterization of continuous fibre composites developed by FFF. To promote the use of these composites for outdoor applications, various moisture environments have been applied (9-98\% RH). Moisture sorption can lead to moisture contents of around 5-6 \% for carbon and glass fibre composites, considering their hygroscopic sensitivity and the necessity to take this into account when designing parts. In fact, moisture induces orthotropic hygroscopic swelling influenced by the original microstructure (repeatable porosities, heterogeneous fibre distribution) of composites as well as the hygroscopic nature of the material. Finally, a reduction of longitudinal and transverse tensile properties is observed. Almost complete reversibility of longitudinal properties can be attained, thus highlighting a main mechanism of plasticization of the PA matrix. In the transverse direction, degradation is only partially reversible, reflecting the drastic effect of the microstructure and defects.

Future work should be achieved on developing customized materials with various type of continuous fibre reinforce composites while applying on a printing machine where printing parameters are open to be modified.

\section{Acknowledgments}

The authors wish to acknowledge "Region Bretagne" for financial support. Dr M.S.N. Carpenter postedited the English style and grammar.

\section{References}

[1] Bogue R. 3D printing: the dawn of a new era in manufacturing? Assem Autom 2013;33:307-11. doi:10.1108/AA-06-2013-055.

[2] Crump S. Apparatus and method for creating three-dimensional objects Available at: https://patents.google.com/patent/US5121329A/en, 1992.

[3] Parandoush P, Lin D. A review on additive manufacturing of polymer-fiber composites. Compos Struct 2017;182:36-53. doi:10.1016/j.compstruct.2017.08.088.

[4] Wang X, Jiang M, Zhou Z, Gou J, Hui D. 3D printing of polymer matrix composites: A review and prospective. Compos Part B Eng 2017;110:442-58. doi:10.1016/j.compositesb.2016.11.034. 
[5] Ngo TD, Kashani A, Imbalzano G, Nguyen KTQ, Hui D. Additive manufacturing (3D printing): A review of materials, methods, applications and challenges. Compos Part B Eng 2018;143:172-96. doi:10.1016/j.compositesb.2018.02.012.

[6] Brenken B, Barocio E, Favaloro A, Pipes RB, Kunc V. Fused fi lament fabrication of fi ber-reinforced polymers : A review. Addit Manuf 2018;21:1-16. doi:10.1016/j.addma.2018.01.002.

[7] Berman B. 3-D printing: The new industrial revolution. Bus Horiz 2012;55:155-62. doi:10.1016/j.bushor.2011.11.003.

[8] https://www.stratasys.com (Accessed May 2018) n.d.:2-3.

[9] https://www.markforged.com/materials/ (Accessed May 2018) n.d.

[10] Tekinalp HL, Kunc V, Velez-Garcia GM, Duty CE, Love LJ, Naskar AK, et al. Highly oriented carbon fiber-polymer composites via additive manufacturing. Compos Sci Technol 2014;105:144-50. doi:10.1016/j.compscitech.2014.10.009.

[11] Ning F, Cong W, Qiu J, Wei J, Wang S. Additive manufacturing of carbon fiber reinforced thermoplastic composites using fused deposition modeling. Compos Part B Eng 2015;80:369-78. doi:10.1016/j.compositesb.2015.06.013.

[12] Ferreira RTL, Amatte IC, Dutra TA, Bürger D. Experimental characterization and micrography of 3D printed PLA and PLA reinforced with short carbon fibers. Compos Part B Eng 2017;124:88-100. doi:10.1016/j.compositesb.2017.05.013.

[13] Liao G, Li Z, Cheng Y, Xu D, Zhu D, Jiang S, et al. Properties of oriented carbon fiber/polyamide 12 composite parts fabricated by fused deposition modeling. Mater Des 2018;139:283-92. doi:10.1016/j.matdes.2017.11.027.

[14] Zhong W, Li F, Zhang Z, Song L, Li Z. Short fiber reinforced composites for fused deposition modeling. Mater Sci Eng A301 2001;301:125-30.

[15] Matsuzaki R, Ueda M, Namiki M, Jeong T-K, Asahara H, Horiguchi K, et al. Three-dimensional printing of continuous-fiber composites by in-nozzle impregnation. Sci Rep 2016;6:23058.

doi:10.1038/srep23058.

[16] Tian X, Liu T, Yang C, Wang Q, Li D. Interface and performance of 3D printed continuous carbon fiber reinforced PLA composites. Compos Part A Appl Sci Manuf 2016;88:198-205.

doi:10.1016/j.compositesa.2016.05.032.

[17] Yamanaka Y, Todoroki A, Ueda M, Hirano Y, Matsuzaki R. Fiber Line Optimization in Single Ply for 3D Printed Composites. Open J Compos Mater 2016;6:121-31. doi:10.4236/ojcm.2016.64012.

[18] Yang C, Wiaoyong T, Liu T, Cao Y, Li D. 3D printing for continuous fiber reinforced thermoplastic composites : mechanism and performance. Rapid Prototyp J 2017;23.

[19] Yamawaki M, Kouno Y. Fabrication and mechanical characterization of continuous carbon fiber- 
reinforced thermoplastic using a preform by three-dimensional printing and via hot-press molding. Adv Compos Mater 2017;3046:1-11. doi:10.1080/09243046.2017.1368840.

[20] Hou Z, Tian X, Zhang J, Li D. 3D Printed Continuous Fibre Reinforced Composite Corrugated Structure. Compos Struct 2017. doi:10.1016/j.compstruct.2017.10.080.

[21] Goh GD, Dikshit V, Nagalingam AP, Goh GL, Agarwala S, Sing SL, et al. Characterization of mechanical properties and fracture mode of additively manufactured carbon fiber and glass fiber reinforced thermoplastics. Mater Des 2017;137:79-89. doi:10.1016/j.matdes.2017.10.021.

[22] Van der Klift F, Koga Y, Todoroki A, Ueda M, Hirano Y, Matsuzaki R. 3D Printing of Continuous Carbon Fibre Reinforced Thermo-Plastic (CFRTP) Tensile Test Specimens. Open J Compos Mater 2016;6:18-27. doi:10.4236/ojcm.2016.61003.

[23] Justo J, Távara L, García-Guzmán L, París F. Characterization of 3D printed long fibre reinforced composites. Compos Struct 2017. doi:10.1016/j.compstruct.2017.11.052.

[24] Dickson AN, Barry JN, McDonnell KA, Dowling DP. Fabrication of continuous carbon, glass and Kevlar fibre reinforced polymer composites using additive manufacturing. Addit Manuf 2017;16:14652. doi:10.1016/j.addma.2017.06.004.

[25] Arhant M, Le Gac PY, Le Gall M, Burtin C, Briançon C, Davies P. Effect of sea water and humidity on the tensile and compressive properties of carbon-polyamide 6 laminates. Compos Part A Appl Sci Manuf 2016;91:250-61. doi:10.1016/j.compositesa.2016.10.012.

[26] Tual N, Carrere N, Davies P, Bonneimans T, Lolive E. Characterization of Sea Water Ageing Effects on Mechanical Properties of Carbon/Epoxy Composites for Tidal Turbine Blades. Compos Part A 2015;78:380-9.

[27] Cheng L, Dwan A, Gryte CC. Isothermal phase behavior of nylon-6,-66, and -610 polyamides in formic acid water systems. J Polym Sci Part B Polym Phys 1994;32:1183-90.

[28] Coroller G, Lefeuvre A, Le Duigou A, Bourmaud A, Ausias G, Gaudry T, et al. Effect of flax fibres individualisation on tensile failure of flax/epoxy unidirectional composite. Compos Part A Appl Sci Manuf 2013;51:62-70. doi:10.1016/j.compositesa.2013.03.018.

[29] Ahn S, Montero M, Odell D, Roundy S, Wright PK. Anisotropic material properties of fused deposition modeling ABS. Rapid Prototyp J 2002;8:248-57. doi:10.1108/13552540210441166.

[30] Afrose MF, Masood SH, Nikzad M, Iovenitti P. Effects of Build Orientations on Tensile Properties of PLA Material Processed by FDM. Adv Mater Res 2014;1045:31-4.

doi:10.4028/www.scientific.net/AMR.1044-1045.31.

[31] Ashby MF. The Mechanical Properties of Cellular Solids. Metall Trans A 1983;14A:1755-69.

[32] Olivier P, Cottu JP, Ferret B. Effects of cure cycle pressure and voids on some mechanical properties of carbon/epoxy laminates. Composites 1995;26:509-15. doi:10.1016/0010-4361(95)96808-J. 
[33] Liu L, Zhang BM, Wang DF, Wu ZJ. Effects of cure cycles on void content and mechanical properties of composite laminates. Compos Struct 2006;73:303-9. doi:10.1016/j.compstruct.2005.02.001.

[34] Zhu H, Wu B, Li D, Zhang D, Chen Y. Influence of Voids on the Tensile Performance of Carbon/epoxy Fabric Laminates. J Mater Sci Technol 2011;27:69-73. doi:10.1016/S1005-0302(11)60028-5.

[35] Varna J, Joffe R, Berglund LA, Lundström TS. Effect of voids on failure mechanisms in RTM laminates. Compos Sci Technol 1995;53:241-9. doi:10.1016/0266-3538(95)00024-0.

[36] Canal LP, Segurado J, LLorca J. Failure surface of epoxy-modified fiber-reinforced composites under transverse tension and out-of-plane shear. Int J Solids Struct 2009;46:2265-74. doi:10.1016/j.ijsolstr.2009.01.014.

[37] Maurin R, Davies P, Baral N. Transverse Properties of Carbon Fibres by Nano-Indentation and Micromechanics. Appl Compos Mater 2008:61-73. doi:10.1007/s10443-008-9057-3.

[38] Park GS. Transport Principles—Solution, Diffusion and Permeation in Polymer Membranes. Synth Membr Sci Eng Appl 1986:57-107. doi:10.1007/978-94-009-4712-2_3.

[39] Broudin M, Le Saux V, Le Gac PY, Champy C, Robert G, Charrier P, et al. Moisture sorption in polyamide 6.6: Experimental investigation and comparison to four physical-based models. Polym Test 2015;43:10-20. doi:10.1016/j.polymertesting.2015.02.004.

[40] Mark HF, Bikales NM, Oberberger CG, Menges G, Kroschwitz JI. Encyclopedia of Polymer Science and Engineering - 2nd edition. vol. 11. 1990. doi:10.1111/j.1365-2141.1990.tb06361.x.

[41] Thomasson JL, Porteus G. Swelling of glass-fiber reinforced polyamide 66 during conditioning in water, ethylene glycol and antifreeze mixture. Polym Polym Compos 2008;16:101-13. doi:10.1002/pc.

[42] Stellrecht E, Han B, Pecht MG. Characterization of Hygroscopic Swelling Behavior of Mold Compounds and Plastic Packages. IEEE Trans Components Packag Technol 2004;27:499-506.

[43] Pérez-Pacheco E, Cauich-Cupul JI, Valadez-González A, Herrera-Franco PJ. Effect of moisture absorption on the mechanical behavior of carbon fiber/epoxy matrix composites. J Mater Sci 2013;48:1873-82. doi:10.1007/s10853-012-6947-4.

[44] Downes KA, Thomason JL. A method to measure the influence of humidity and temperature on the interfacial adhesion in polyamide composites. Compos Interfaces 2015;22:757-66.

doi:10.1080/09276440.2015.1059114.

[45] Duty CE, Kunc V, Compton B, Post B, Erdman D, Smith R, et al. Structure and Mechanical Behavior of Big Area Additive Manufacturing ( BAAM ) Materials. Rapid Prototyp J 2017;23.

[46] Ferreira R, Aeronáutica IT De, Thiago R, Ferreira L, Amatte IC, Daniel B. Experimental characterization and micrography of 3D printed PLA and PLA reinforced with short carbon fibers Experimental characterization and micrography of 3D printed. Compos Part B Eng 2017;124:88-100. doi:10.1016/j.compositesb.2017.05.013. 
[47] Properties of Wrought Aluminum and Aluminum Alloys. ASM Handbook, Vol 2 Prop Sel Nonferrous Alloy Spec Mater n.d.;2:62-122. doi:10.1361/asmhba000.

[48] Botelho EC, Figiel, Rezende MC, Lauke B. Mechanical behavior of carbon fiber reinforced polyamide composites. Compos Sci Technol 2003;63:1843-55. doi:10.1016/S0266-3538(03)00119-2. 


\section{Figures}
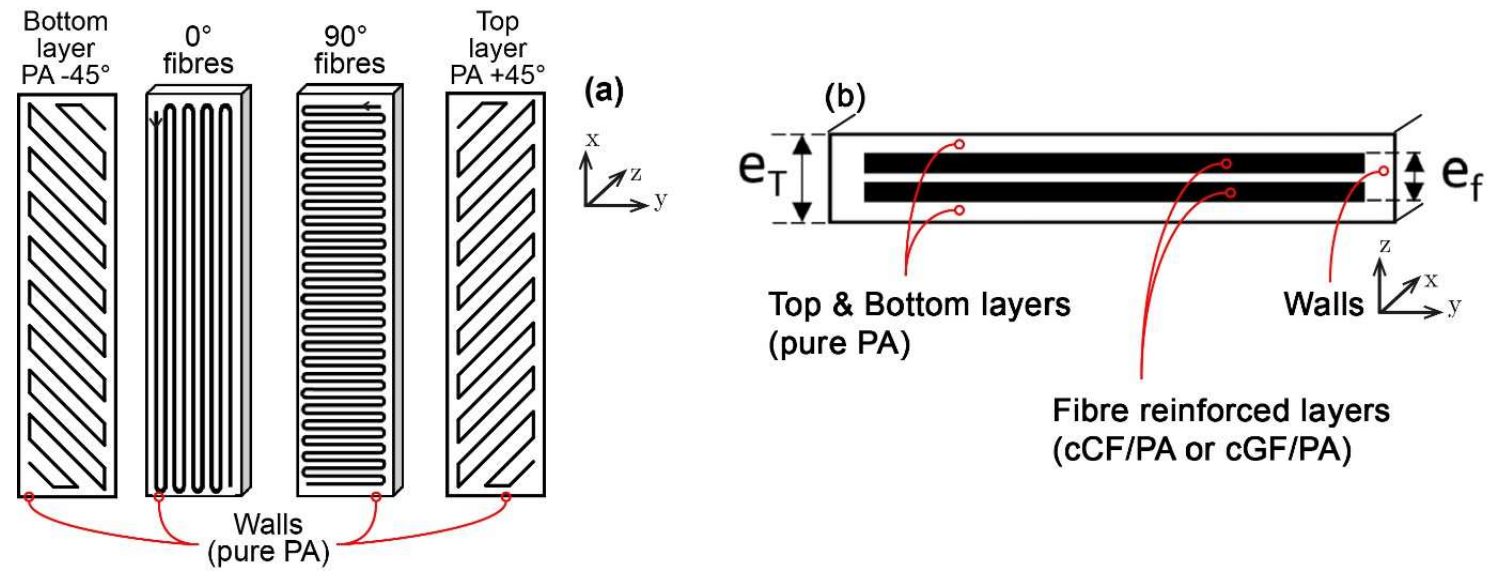

Figure 1 : Schematic views of (a) a continuous fibre reinforced printed part in (x, y, z) coordinate system, and (b) crosssection illustrating 'Top \& Bottom' as well as reinforced layer sequence $\left(\mathrm{e}_{\mathrm{T}}\right.$ represents the total thickness and $\mathrm{e}_{\mathrm{f}}$ the fibre reinforced layer thickness).

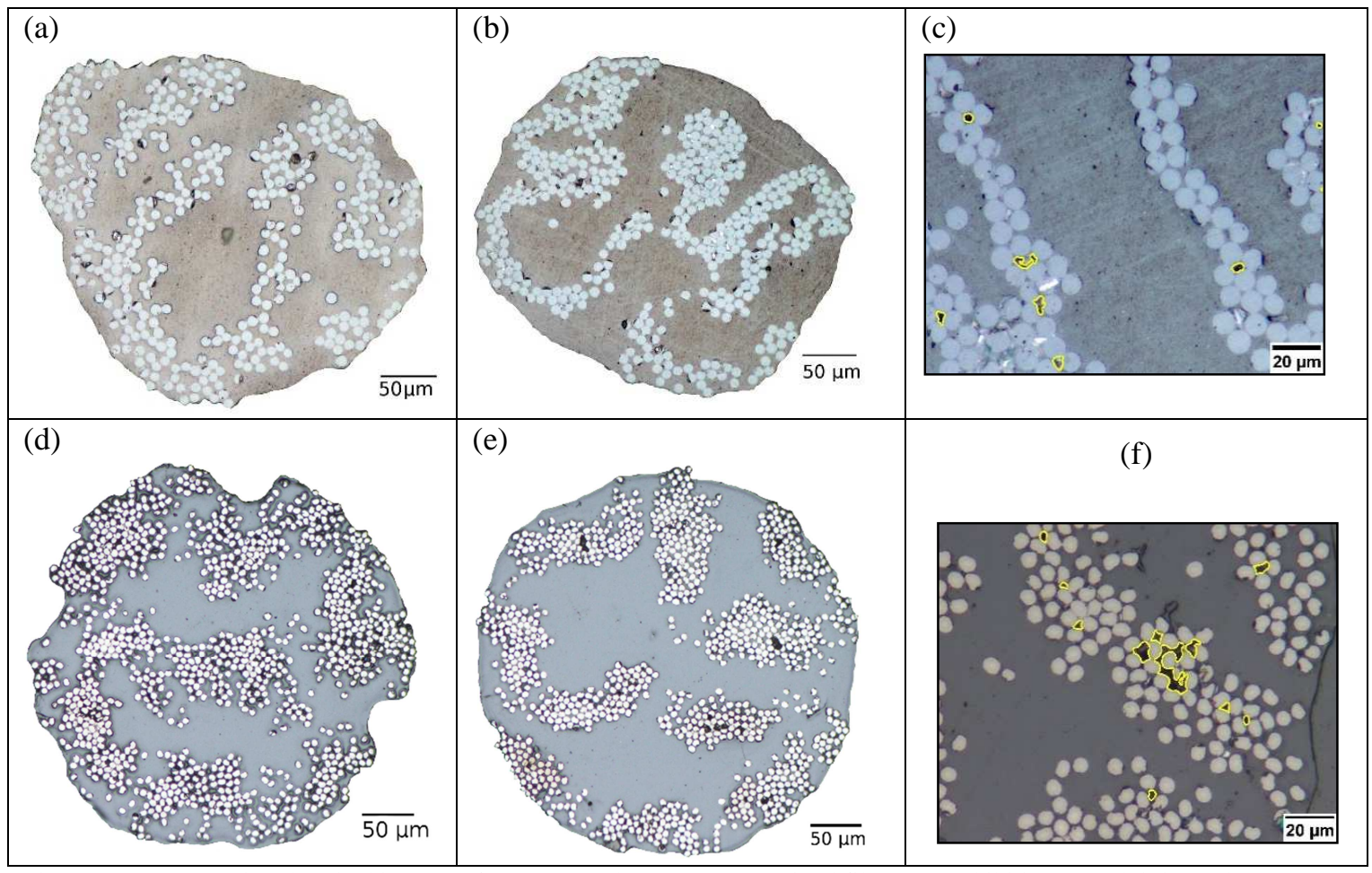

Figure 2 : Cross-sectional optical images of cGF/PA and cCF/PA as received filaments exhibiting (a and d) irregular outer limits, (b and e) regular circumference and (c and f) magnified views 

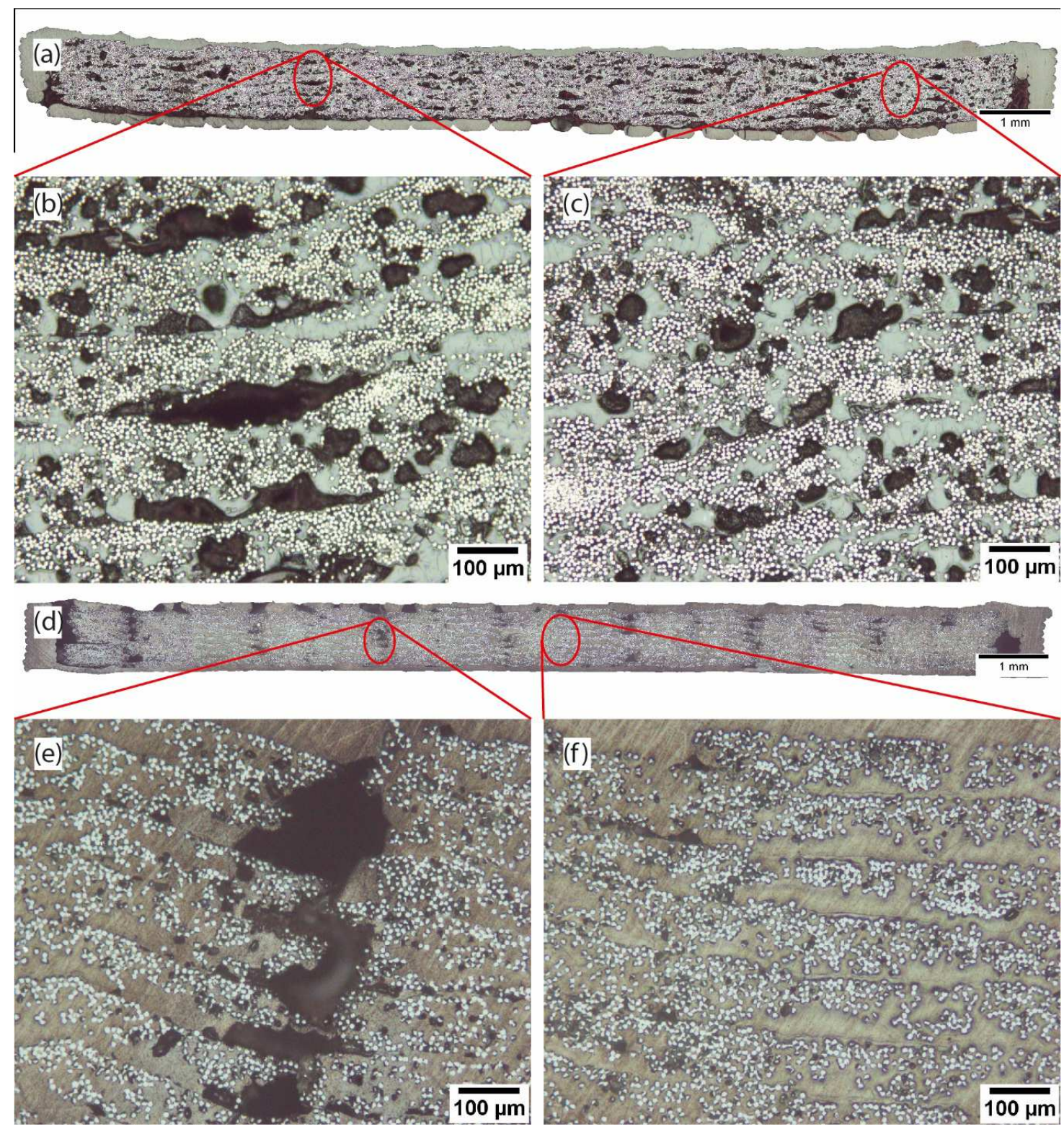

Figure 3 : Microstructure of cross-sectionned (a) cCF/PA and (d) cGF/PA printed part under optical microscope and magnification in areas where printed beads are not overlapped for (b) cCF/PA and (e) cGF/PA along with magnification in areas in the printed beads of (c) cCF/PA and (f) cGF/PA highlighting intra and inter-bead porosities.

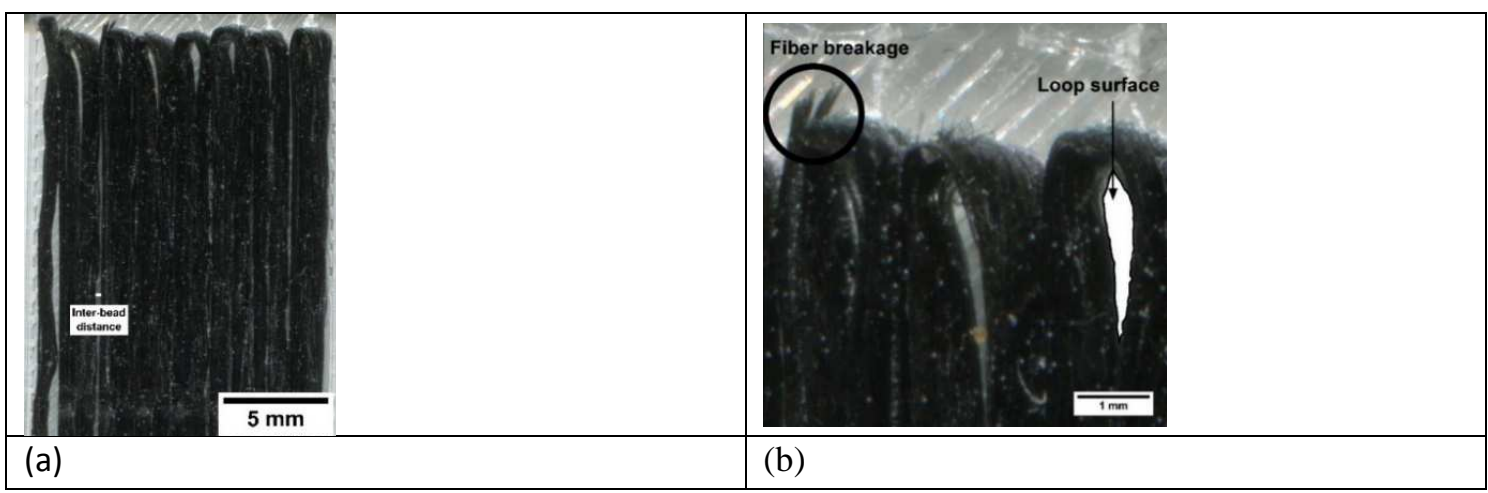




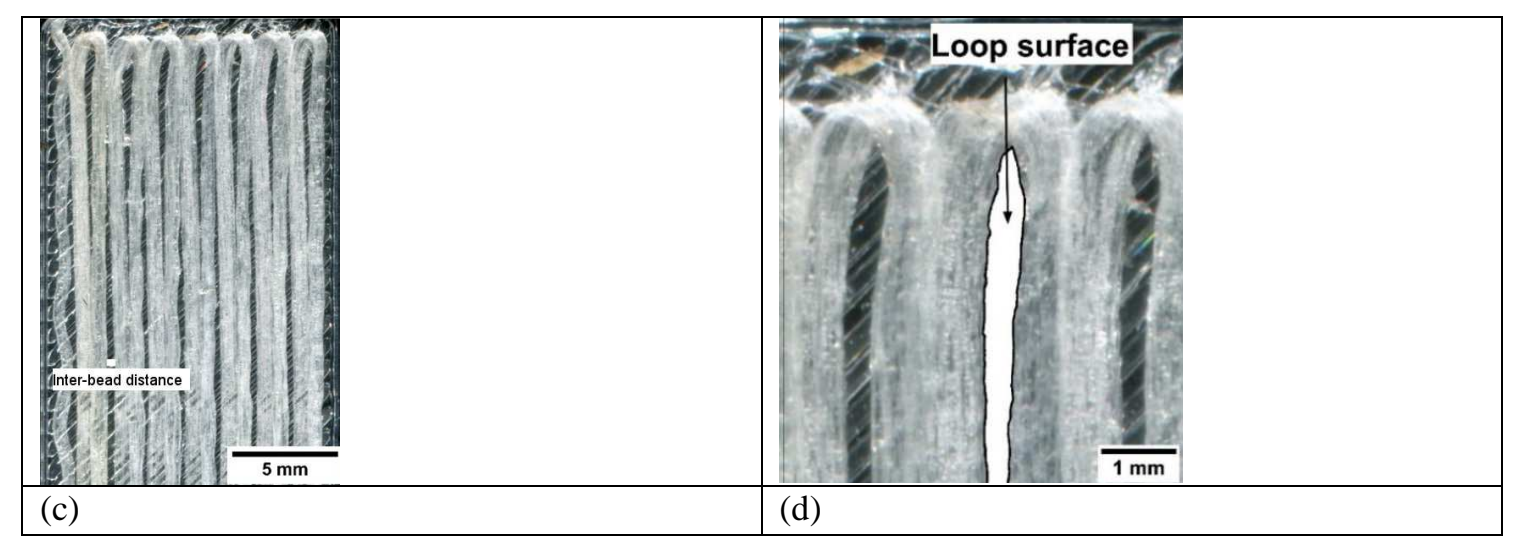

Figure 4 : Optical images of single printed layer of $(a, b) c C F / P A$ and $(c, d) c G F / P A$ printed filament, with a higher magnification of their respective folding area given in (b) and (d).
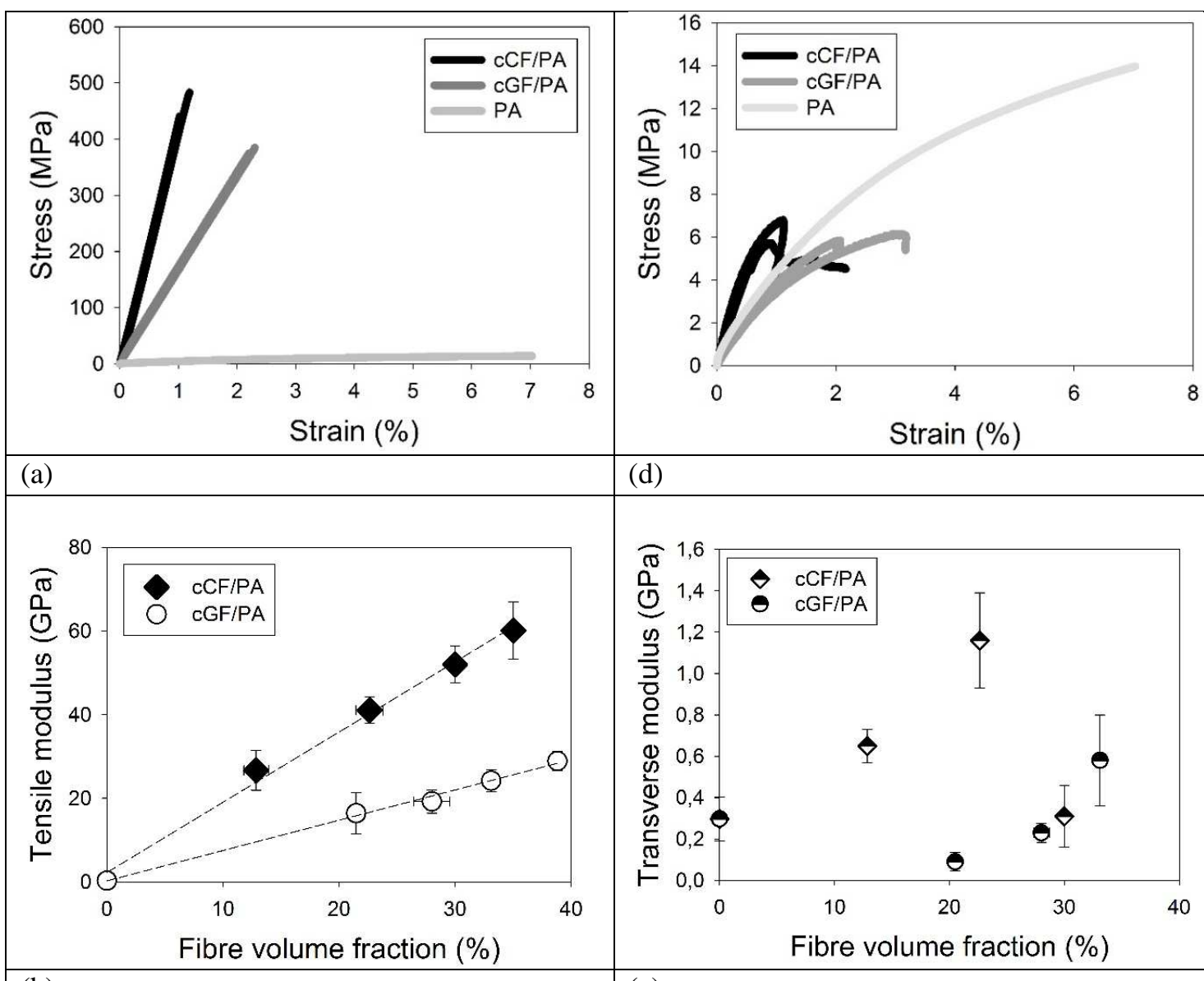

(d)

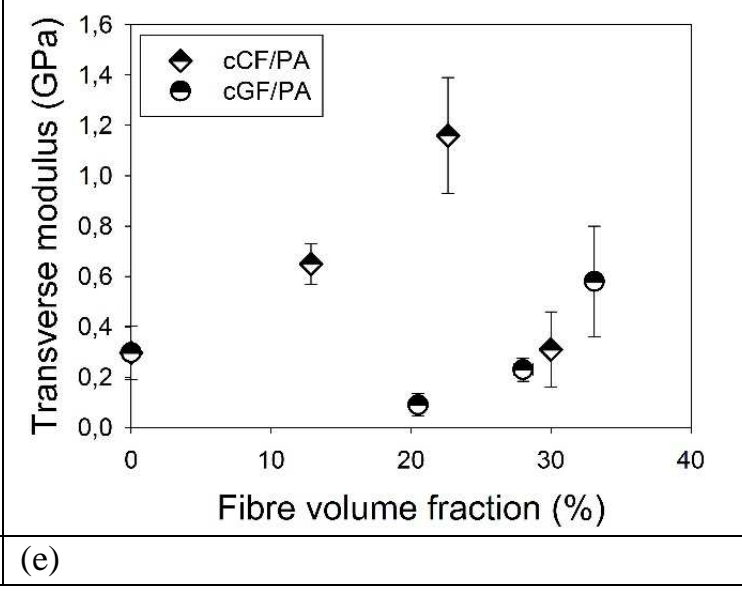




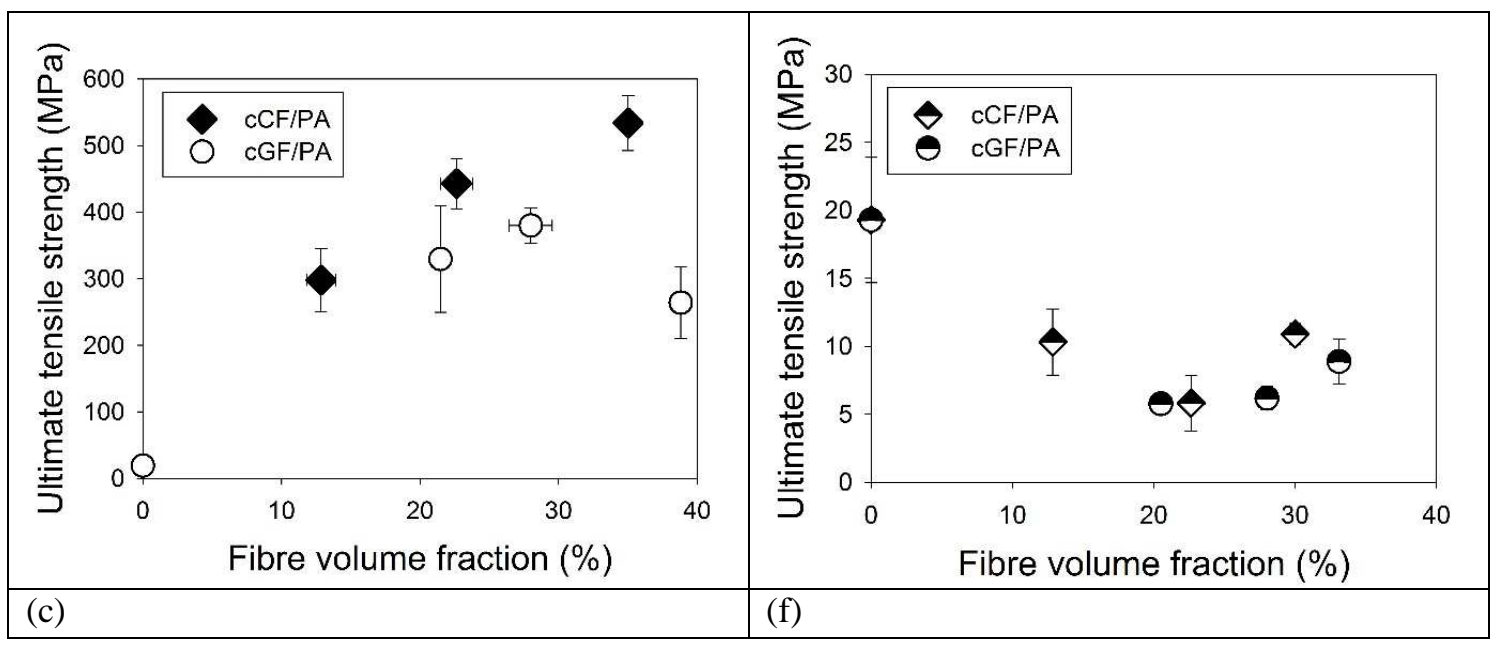

Figure 5: Typical tensile stress vs. strain behavior of PA, cGF/PA, and cCF/PA printed parts tested in (a) longitudinal and ((d) transverse direction. Tensile modulus and strength of cGF/PA and cCF/PA as a function of fibre volume content in (b,c) longitudinal and $(e, f)$ transverse directions, respectively.

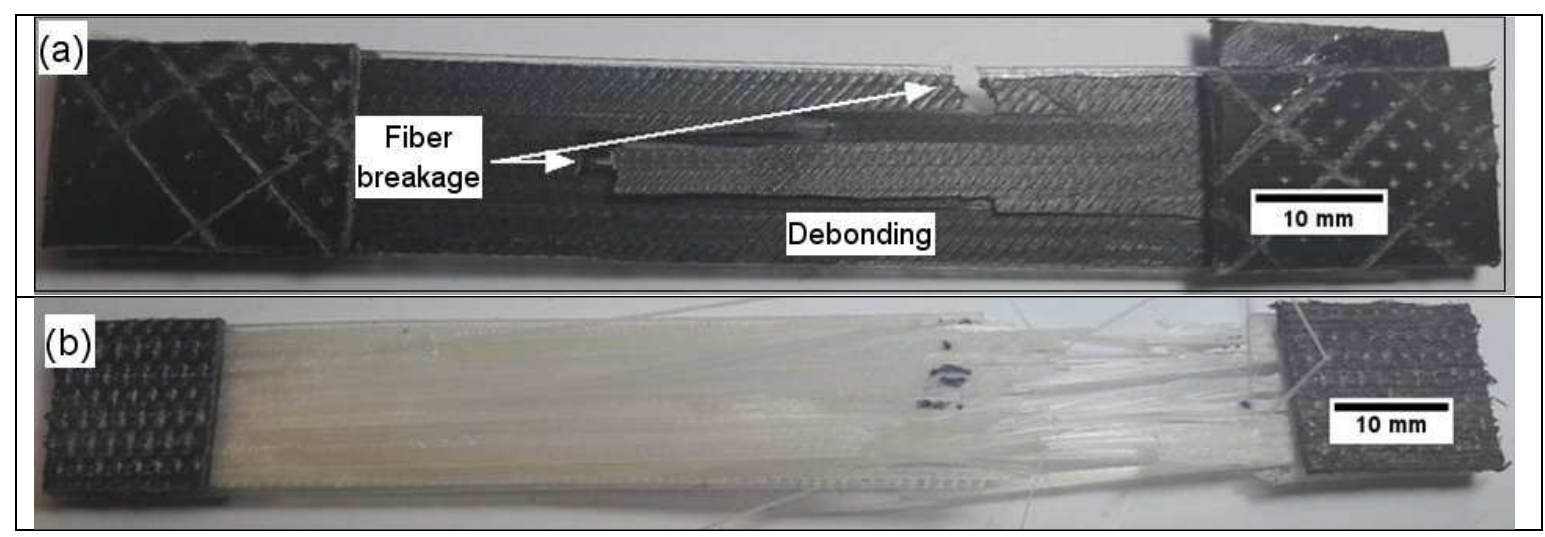

Figure 6 : Optical images of fractured (a) cCF/PA and (b) cGF/PA showing fracture mode for each sample which results in fibre breakage and debonding between printed beads

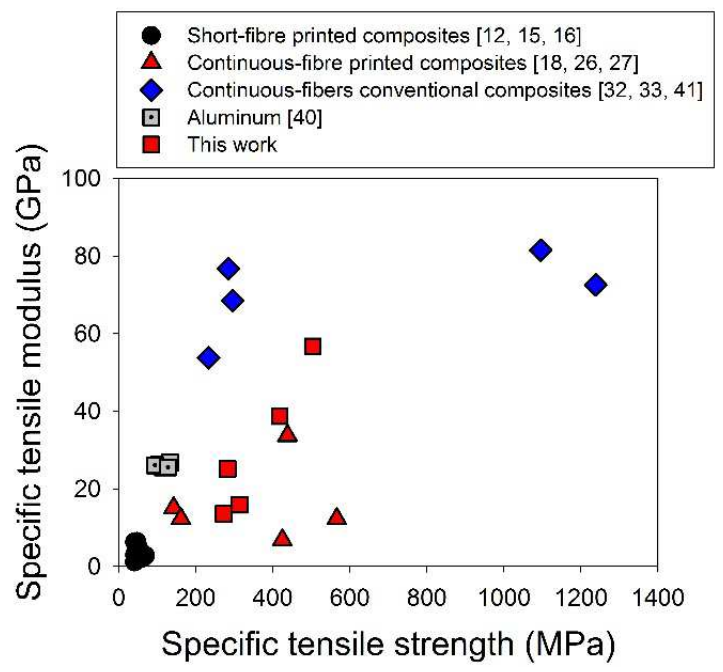

Figure 7: Comparison of specific mechanical properties obtained in this study with literature data for short-fibre printed composites, continuous-fibre printed composites, aluminium and conventionally-manufactured composites $[13,15,21,22,25,26,45-48]$ 


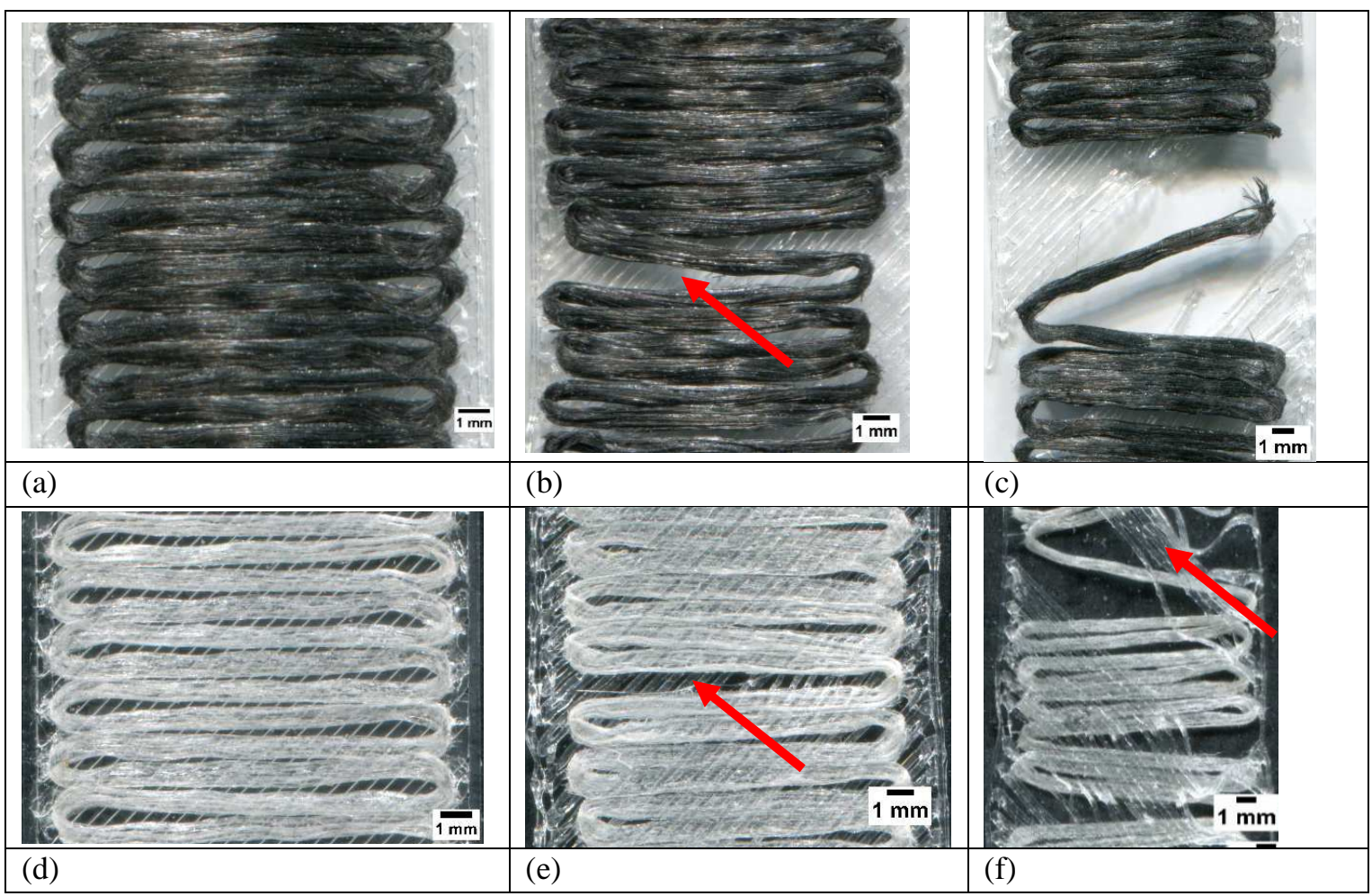

Figure 8: Evolution of transverse sample profile during tensile tests for cCF/PA (a,b,c) and cGF/PA (d,e,f) samples at different testing strain; $(\mathrm{a}, \mathrm{d})$ representing initial stage, $(\mathrm{b}, \mathrm{e})$ the part at strain-at-break and $(\mathrm{c}, \mathrm{f})$ an ?excessive strain showing unwinding and rupture of the printed bead.

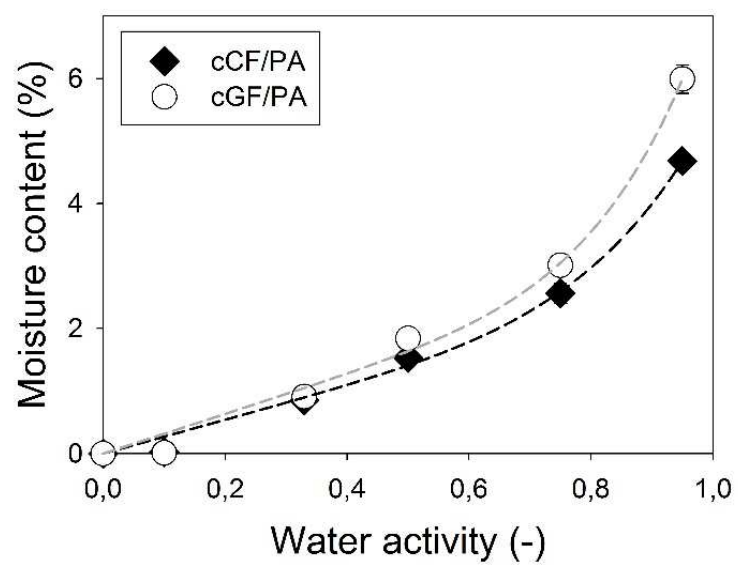

Figure 9 : Evolution of moisture content for $\mathrm{CCF} / \mathrm{PA}$ and cGF/PA printed parts as a function of water activity (dashed line represents fit with Park model) 

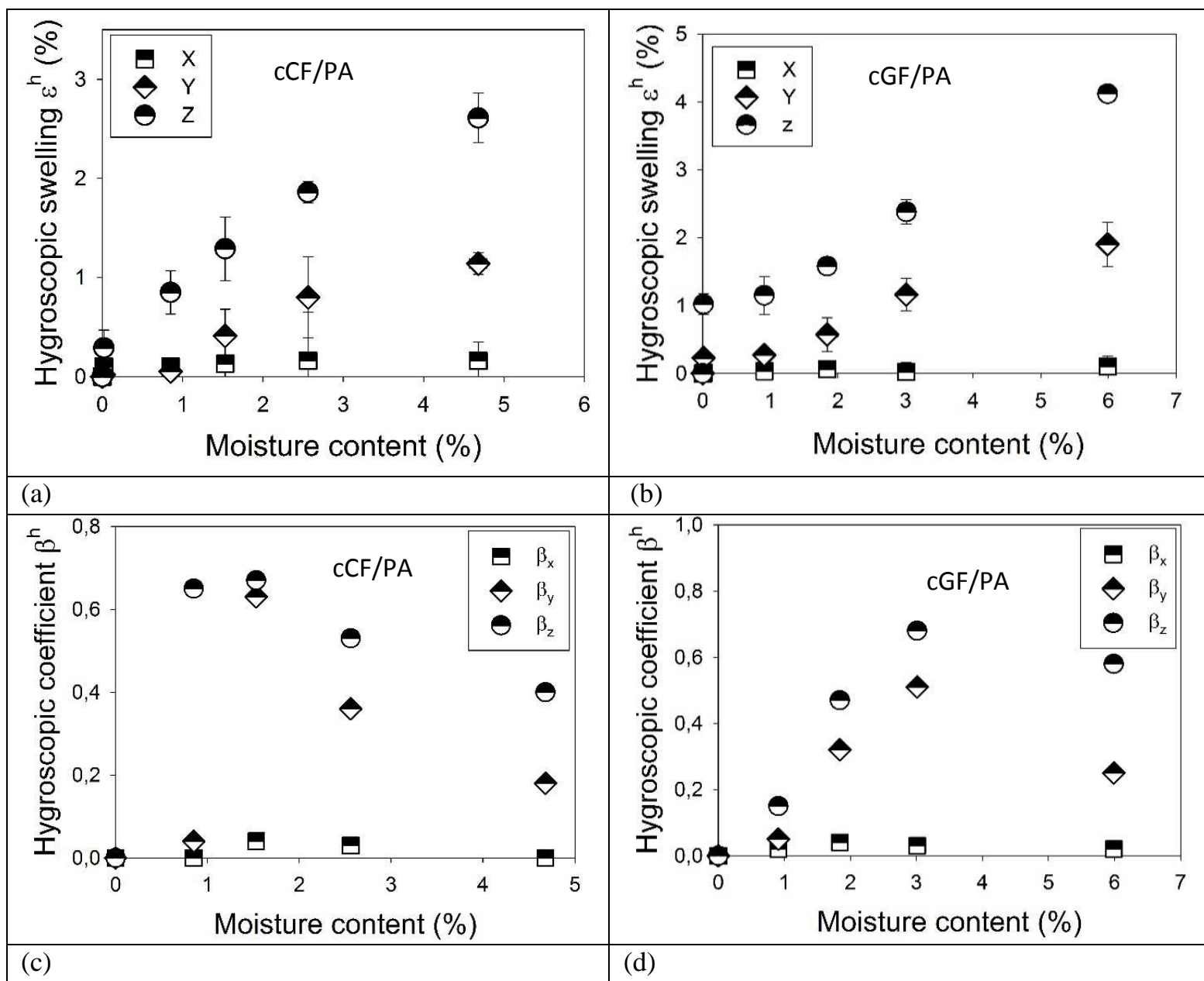

(c)

(d)

Figure 10 :Hygroscopic swelling of (a) cCF/PA and (b) cGF/PA and hygroscopic coefficient $\beta$ of (c) cCF/PA and (d) cGF/PA in $\mathrm{x}, \mathrm{y}$ and $\mathrm{z}$ direction as a function of moisture content.

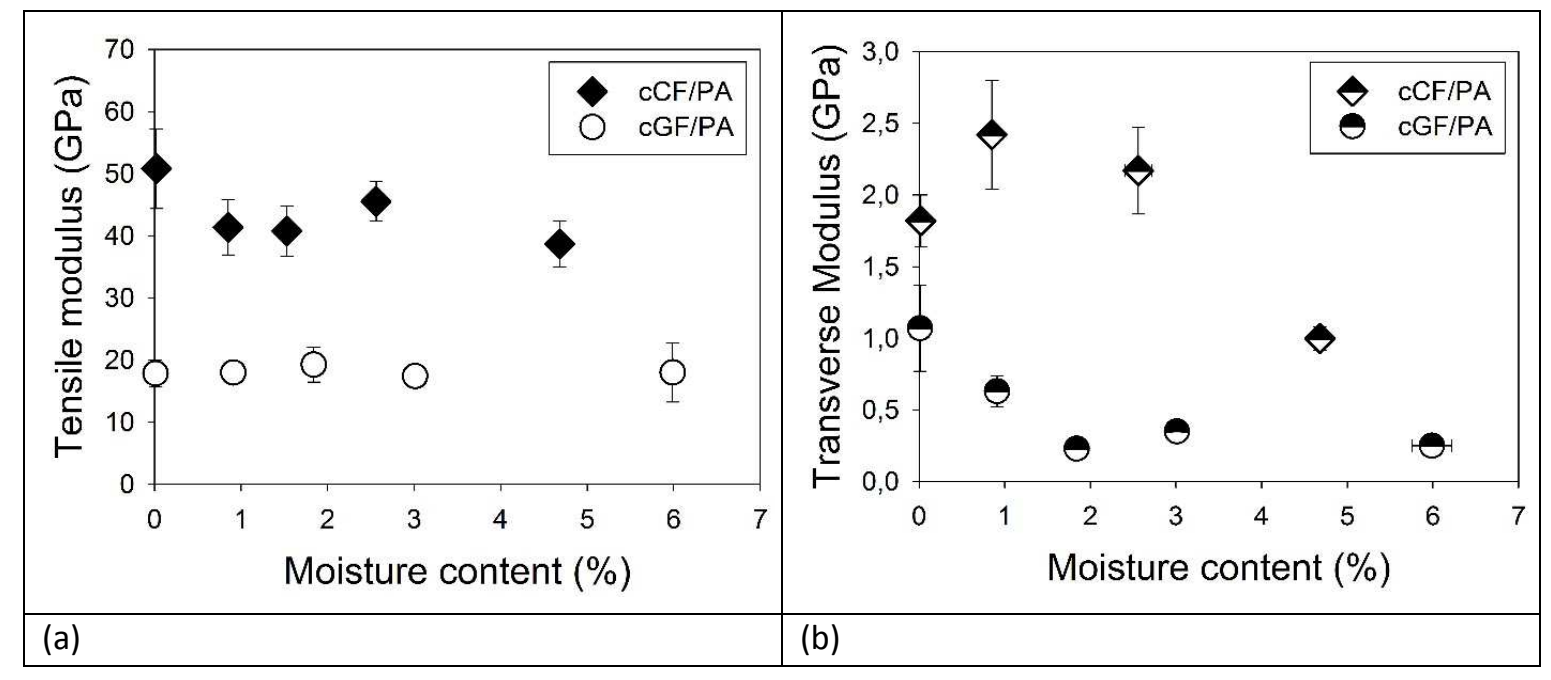




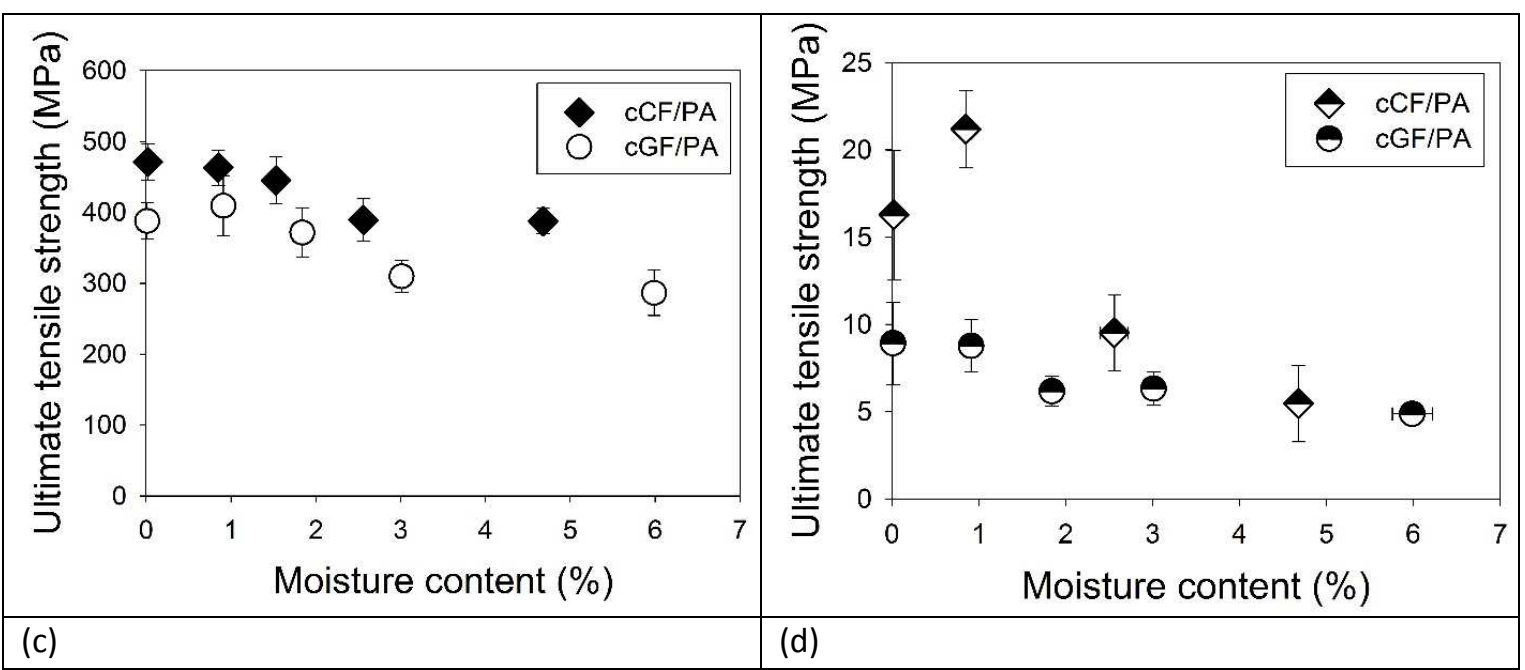

Figure 11: Tensile modulus and ultimate strength of cCF/PA and cGF/PA printed parts, respectively, in (a, c) longitudinal and $(b, d)$ transverse direction after being moisture saturated. 


\section{Tables}

Table 1 : Printing configuration illustrating the stacking sequence, total thickness, fibre volume fraction and number of carbon or glass fibre reinforced layers.

\begin{tabular}{|c|c|c|c|c|c|}
\hline \multirow[t]{2}{*}{ Printing configurations } & \multirow{2}{*}{$\begin{array}{l}\text { Total } \\
\text { thickness } \\
(\mathrm{mm})\end{array}$} & \multicolumn{2}{|c|}{$\begin{array}{l}\text { Fibre volume fraction } \\
(\%)\end{array}$} & \multicolumn{2}{|c|}{ Number of fibre reinforced layer(s) } \\
\hline & & Carbon & Glass & Carbon & Glass \\
\hline & 0.5 & 12.9 & 21.5 & 2 & 3 \\
\hline & 1 & 22.6 & 28 & 6 & 8 \\
\hline & 2 & 30 & 33.1 & 14 & 18 \\
\hline
\end{tabular}

Table 2 : Geometrical characteristics and porosity content for as received samples of cCF/PA and cGF/PA filament and printed parts.

\begin{tabular}{lllll}
\hline Sample & & Filament diameter $(\mu \mathrm{m})$ & Layer thickness $(\mu \mathrm{m})$ & Porosity $(\%)$ \\
\hline \multirow{2}{*}{ Filament } & $\mathrm{cCF} / \mathrm{PA}$ & $379,8 \pm 10,5$ & $/$ & $1,85 \pm 0,3$ \\
& $\mathrm{cGF} / \mathrm{PA}$ & $332,0 \pm 23,2$ & $/$ & $1,34 \pm 0,13$ \\
\multirow{2}{*}{ Printed part } & $\mathrm{cCF} / \mathrm{PA}$ & $/$ & $127,9 \pm 22,7$ & $15,10 \pm 0,35$ \\
& $\mathrm{cGF} / \mathrm{PA}$ & $/$ & $100,8 \pm 4,6$ & $12,30 \pm 0,65$ \\
\hline
\end{tabular}

Table 3 : Geometrical characteristics of in-plane images of single layer cCF/PA and cGF/PA printed parts.

\begin{tabular}{llll}
\hline Material & Loop surface $\left(\mathrm{mm}^{2}\right)$ & Inter-bead gap $(\mathrm{mm})$ & Turning radii $(\mathrm{mm})$ \\
\hline cCF/PA & $0.42 \pm 0,12$ & $0,13 \pm 0,04$ & $0,62 \pm 0,07$ \\
cGF/PA & $1.04 \pm 0,26$ & $0,31 \pm 0,06$ & $0,66 \pm 0,06$ \\
\hline
\end{tabular}



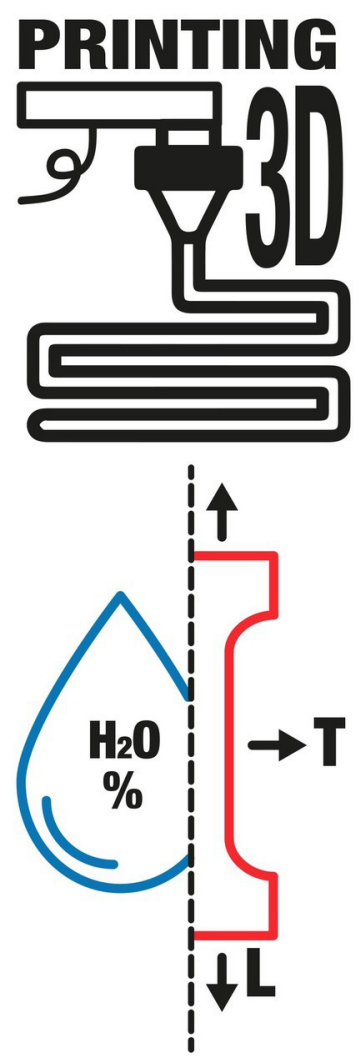
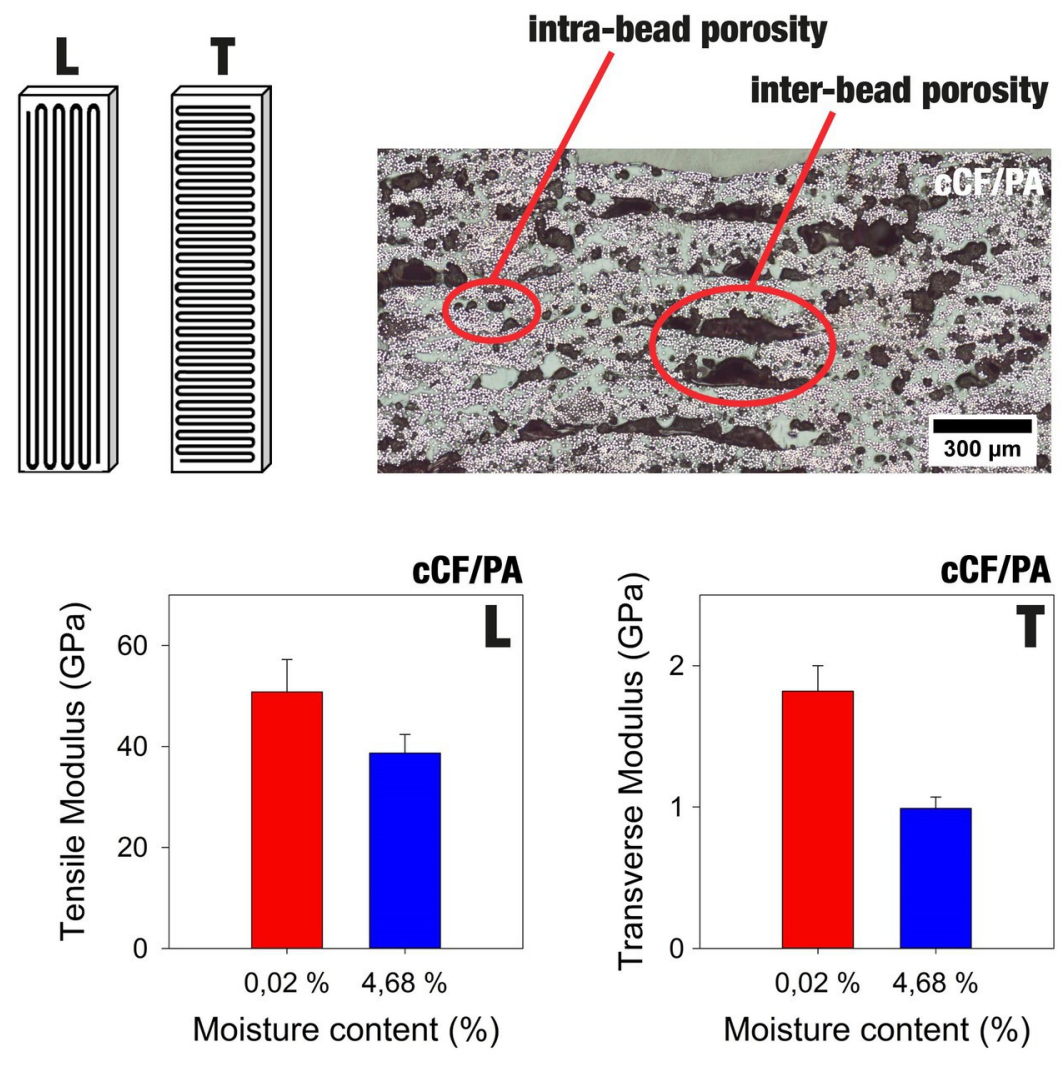